\title{
Willingness-to-Pay for Natural, Organic, and Conventional Foods: The Effects of Information and Meaningful Labels ${ }^{\dagger}$
}

\author{
Jonathan R. McFadden ${ }^{\mathrm{a}, *}$ and Wallace E. Huffman ${ }^{\mathrm{b}, * *}$ \\ ${ }^{a}$ Economic Research Service, U.S. Department of Agriculture, 1400 Independence Ave., SW Mail Stop \\ 1800, Washington, DC 20250-1800, United States \\ ${ }^{\mathrm{b}}$ Department of Economics, Iowa State University, 460E Heady Hall, Ames, IA 50011-1054, \\ United States
}

\begin{abstract}
Vague food labels and distorted product claims have persisted in the "natural" food industry, while organic claims can be certified by the U.S. Department of Agriculture (USDA). Using experimental methods and a sample of randomly selected subjects, we test food label and information treatment effects on subjects' willingness-to-pay (WTP) for organic, "natural," and conventional foods. Random $n$ th-price auctions are used to elicit WTP after subjects received one of five randomly assigned information treatments. We find large information effects, including asymmetric cross-market effects for natural and organic foods. Perhaps surprising is that organic premiums increase in response to subjects seeing the "natural" foods industry's perspective on its products. Demographics effects are also important. The results have practical implications for natural and organic food marketing and valuing products where there are vague claims about their attributes.
\end{abstract}

Keywords: Experimental auctions, organic foods, "natural" foods, information effects, food labels, random $n$ th-price auction

\footnotetext{
${ }^{*}$ The experiment was completed while at Iowa State university.

** Corresponding author. E-mail address: whuffman@iastate.edu (W.H. Huffman).
} 


\section{Introduction}

Organic farming and sales of organic foods and food products in the U.S. have grown steadily since the Organic Food Production Act (OFPA) of 1990 and implementation of the National Organic Program (NOP) in 2002. U.S. organic food sales have increased more than $160 \%$ from $\$ 13.3$ billion in 2005 to an estimated \$35 billion in 2014 (USDA-ERS, 2016). In recent years, roughly 9,000 to 14,000 U.S. certified organic operations have farmed 3.6 to 4.1 million acres (USDA-NASS, 2010; USDA-NASS, 2012). Domestic supply has responded to broad-based demand increases from consumers (e.g., farmers' markets, stands, and communitysupported agriculture), wholesalers, and retailers (e.g., grocery stores and restaurants).

The growth of organic agriculture can be partially attributed to NOP's clear guidelines and certification procedures. Organic products cannot be made with conventional pesticides and fertilizers, herbicides, biotechnologies, irradiation, and sewage sludge, though there is a list of approved synthetic substances. Animals must have access to the outdoors and cannot receive growth hormones or antibiotics. Foods that have been organically produced and contain at least 95\% organic ingredients may display the USDA organic seal (National Organic Program, 2002).

This contrasts greatly with "all natural" or " $100 \%$ natural" food products (hereafter termed "natural" foods), which lack a set of guidelines or legally-binding regulations. The USDA's Food Safety and Inspective Service (USDA-FSIS), which regulates meat and poultry, implemented an informal policy on "natural" foods labeling starting in 1982. Its current "natural" informal policy for meat and poultry disallows artificial flavoring, coloring ingredients, chemical preservatives, and processing above minimal levels (USDA-FSIS, 2005). The Food and Drug Administration (FDA) regulates the majority of U.S. food products and has maintained a similar informal policy since 1991. Although it does not have a stringent definition for "natural" foods, 
FDA has considered "natural" to mean the exclusion of artificial or synthetic substances that would not normally be expected to be there (US-HHS-FDA, 1991).

Recent requests for legal "natural" standards from various interests, including Hormel Foods, Sara Lee Corporation, and The Sugar Association, have highlighted the adverse market consequences in the absence of a uniform and unambiguous policy. Differing interpretations of "natural" have contributed to increases in costly lawsuits against producers (Negowetti, 2013). There continues to be substantial misunderstanding among consumers about the differences (real or perceived) between organic and "natural" foods (Anstine, 2007). Indeed, FDA has recently filed a formal request for information and comments on use of the term "natural" in food product labeling (US-HHS-FDA, 2015). There is interest, inter alia, about the extent to which consumers are confusing or conflating "natural" foods with "organic" or "healthy" foods. The comment period has ended, and FDA is currently determining the appropriateness of a "natural" definition and appropriate use in food labeling.

Some of consumers' misunderstanding regarding the various attributes of "natural" and organic foods may result from differing or opposed perspectives contained in information sources. For example, profit-maximizing firms in the "natural" foods and organic foods industries provide information that promotes their products, while certain scientists, regulatory agencies, and public health officials may take a more independent and impartial view. Importantly, the provision of independent, third-party, verifiable information can have substantial effects on buyers' decisions (Milgrom and Roberts, 1986; Rousu et al., 2007). Efficient decision making may hinge on a high degree of competition among information suppliers and skepticism on the part of the consumer. Given expanding consumer interest in "natural" and organic foods, an interesting economic question arises: how do individuals' 
willingness-to-pay (WTP) for these types of foods respond to industry information or both industry and independent, third-party information?

Eliminating these sources of misunderstanding and asymmetric information would lead to better-informed choices, reduce suboptimal consumption, and decrease legal risks of production. This would likely increase welfare in organic, "natural," and other food markets (Hamilton and Zilberman, 2006). The best methods for introducing higher quality information and improving access to such information is unknown, in part because the industry is much smaller than conventional agriculture. Though the majority of U.S. consumers have some experience with these foods, organic sales comprised roughly five percent of total U.S. food sales in 2015, with producers bearing relatively high production costs (Organic Trade Association, 2016; Greene et al., 2009; Klonsky, 2012; McBride et al., 2015). Expansion of the "natural" and organic sector hinges on inducing more consumers to pay price premiums over conventional products, e.g., influencing purchase decisions by increasing WTP.

The objective of this study is to test for food label and information treatment effects reflected in real consumers' WTP for organic, "natural," and conventional foods. To be able to do this, we collect unique data from lab experiments performed on a random sample of 102 adults aged 18-65 years in a Midwestern city during April, 2013. Random $n$ th-price auctions were used to elicit each subject's WTP because of its superior performance in practice and its incentive compatibility properties, i.e., the bidder's dominant strategy is to truthfully reveal her valuation. The experimental, labeled commodities used to assess WTP are Red Delicious apples, fresh broccoli, and large brown eggs. We chose these commodities because they are common and regularly-consumed fresh products available across the three types and are sufficiently different to capture subjects' heterogeneity in tastes. Each subject is randomly assigned to one of five 
information treatments: (i). no information baseline, (ii). "natural" food industry perspective, (iii). "natural" food industry perspective plus independent perspective on "natural" foods, (iv). organic food industry perspective, and (v). organic food industry perspective plus independent perspective on organic foods.

Our study is unique in that it focuses on a range of food products (fruits, vegetables, and eggs) across the conventional, "natural," and organic types. We expand the literature on information, labeling, and valuation of "natural" and organic foods with several contributions. First, our value of information estimates show that subjects' WTP is significantly affected by information treatments. Relative to those who are uninformed, subjects receiving the organic industry perspective plus independent perspective on organics have lower organic premiums, while those receiving the "natural" food industry perspective have higher premiums. This suggests there could be sizeable economic benefits for clearing up misconceptions about these foods with more accurate information and labeling. Second, we find that subjects' demographics have broader and more important effects than previously thought, especially regarding children in the household. Our results reflect the fact that the "natural" and organics industries are now reaching a broader customer base, with customers who cannot be adequately characterized by a handful of demographics. Third, we confirm that subjects are willing to pay premiums for "natural" foods over conventional, as well as for organic foods over "natural." Valuations are increasing in perceived wholesomeness and have remained generally high despite recent growth in the industry.

The remainder of the paper is organized as follows. Section 2 surveys the literature on valuation of "natural" and organic foods, with an emphasis on economics experiments. Section 3 describes the experimental design, while section 4 previews the econometric model and reviews 
the sample data. Section 5 presents the regression results and value of information estimates, and discusses economic implications for the food industry and organic agriculture. Section 6 concludes. The appendix contains a table providing counts and proportions of zero bids, in addition to the four information perspectives used in the experiment.

\section{Related Research}

Early research on the modern "natural" and organics sector focused on growth in response to concerns about pesticide-risk reductions, and sought to identify setbacks related to market expansion, primarily on wholesalers, distribution channels, and consumer demand determinants (Jolly, 1989; Misra et al., 1991; Huang, 1996). ${ }^{1}$ Park and Lohr (1996) document several sources of supply uncertainty as standard explanations for the small share of organics in total agricultural output. However, their system of supply and demand estimates for organic produce indicate that demand factors are more important for market growth and recommend certain measures to increase demand, e.g., advertising targeted to high-income shoppers. Identifying the demographics of "natural" and organics grocery shoppers was particularly challenging before more recent industry expansion. Much of this research is analyses of survey data from private groups or academic researchers for foods in various locations. The primary shopper's age, education, income, marital status, and number and age of children are significant variables, but there have been conflicting findings (Thompson, 1998).

Additional research has centered on consumer demographics, implicitly recognizing the importance of demand considerations. Many studies in the literature analyze demand determinants and price premiums for organic foods using Nielsen Homescan datasets for years

\footnotetext{
${ }^{1}$ See Govindasamy and Italia (1999) for a useful discussion about the early conflicting results surrounding the effects of consumer demographics on purchase intentions and WTP for pesticide-free and organic food products.
} 
2003-2006. ${ }^{2}$ This line of inquiry shows that organic purchases and premiums vary by food product (e.g., fresh fruits and vegetables, meat and dairy, packaged foods), region, seasonality, store type (e.g., traditional grocery store, specialty food store, supercenter, or warehouse club), household attributes, and particular year in which the scanner data are used for analysis.

Using 2003 Nielsen data, Zhang et al. (2008) show that urban households with higher incomes and a household head with higher education have relatively more purchases of organic produce, though effects of young children and household size are negligible. In 2004, shoppers paid premiums of $7.4-17.3 \%$ for organic tomatoes over conventional tomatoes, with marginal WTP for packaged tomatoes ranging in $\$ 0.26-\$ 1.02 / 1 b$ (Huang and Lin, 2007). In the same year, Dettmann and Dimitri (2009) find that the main consumers of organic vegetables tend to be white and well-educated, with relatively high incomes. Using 2005 Nielsen data, the price premium for popular organic fruits, relative to conventional fruits, is found to be $20-42 \%$, while the premium for organic vegetables ranges in 15-60\% (Lin et al., 2008). In 2006, the demand for conventional fruits was found to be price-elastic (-1.06 to -3.54$)$, while the demand for organic fruits was found to be price-inelastic, -0.49 to -0.85 (Lin et al., 2009). Similarly, in 2006, the price premiums for organic milk ranged in 60-109\% above conventional milk, with little effect of shopper demographics (Smith et al., 2009).

In a more recent examination of consumer demographics, Dimitri and Dettmann (2012) analyze the 2006 Nielsen Homescan dataset of 44,000 U.S. households. Higher education and income, access to organic food, and being married increase the likelihood of buying organics, but ethnicity is unimportant. However, these studies and similar research have well-known

\footnotetext{
2 The Nielsen Homscan data comprise a stratified, random sample of several thousand representative U.S. households. After these households buy groceries, they use their home scanner to enter their purchases into the Nielsen database using the products' Universal Purchasing Codes (UPC). Random-weight produce without UPCs use a separate Nielsen coding system. The database also contains extensive information about the demographics of its sample.
} 
methodological weaknesses. Contingent choice studies using on-site interception can have selfselection and hypothetical biases. Analysis of scanner data can incur self-selection, nonreporting, and attrition biases. Our study eliminates these biases via an experiment with several layers of randomization and an incentive-compatible elicitation mechanism.

Batte et al. (2007) analyze WTP premiums for foods that are 100\% organic, at least $95 \%$ organic, at least $70 \%$ organic, and foods containing some organic ingredients (less than $70 \%$ organic) in an intercepted sample of 199 Ohio grocery store shoppers. They find that prior awareness of the NOP increases the probability of willingness to pay a premium for foods with organic ingredients, whereas health concerns are insignificant. Families with children are willing to pay higher premiums for foods that are organic or made with organic ingredients, conditional on willingness to pay a premium.

Assessing consumer WTP with demand-revealing auctions in economics experiments has brought substantial improvements to the food valuation literature. This line of inquiry often uses labeling treatments and/or information treatments for inference on novel food products, production processes, or food consumption trends. Menkhaus et al. (1992) is an early experiment implementing fifth-price auctions to value vacuum-sealed packaging for beef steaks. Information about the benefits of vacuum-sealing and demonstrations increase subjects' premiums for vacuum-sealed beef steaks over conventional packaging (overwrapped Styrofoam trays) by $\$ 0.41-\$ 0.48$, and steaks with an "all natural" label have a $\$ 0.12$ premium. In an experiment valuing tortilla chips, vegetable oil, and potatoes, Huffman et al. (2003) find a 14\% discount of genetically modified (GM)-labeled foods relative to those with conventional labels, with no role for demographic effects. Subsequent analysis demonstrates that information effects on bidding behavior depends on subjects' prior GM knowledge (Huffman et al., 2007). 
Other experimental methods have been applied to examine underlying components of "natural" and organic foods. A series of recent papers tests whether WTP for organic foods, as a whole, equals the sum of WTP for individual components of organic production. Bernard and Bernard (2009) use Vickrey (1961) auctions to elicit subjects' valuations of conventional, rBSTfree, antibiotics-free, and organic milk. Their study finds that the sum of WTP for rBST-free and antibiotics-free milk exceeds WTP for the remaining attributes of organic production. Subjects who are more educated, older, male, primary household shoppers, and have higher incomes have higher WTP for milk with differing organic components.

These results are similar to those in Bernard and Bernard (2010), a WTP experiment on conventional, pesticides-free, GM-free, and organic sweet corn and potatoes. Participants who believe that conventional foods are made with GM technologies or pesticides have higher WTP for GM-free or pesticides-free foods. This echoes another experimental finding of increased WTP for apples produced without pesticides, after controlling for cosmetic damage (Roosen et al., 1998). However, some evidence suggests that valuations for organic foods decrease after learning about non-GM requirements (Gifford and Bernard, 2011). Analyzing bids for "natural," free-range, non-GM-fed, and organic boneless/skinless chicken, the authors conclude that premiums for organic over "natural" decrease after subjects receive information on legal requirements for both food types, likely due to lower criteria for "natural" foods. The experimental information does not contain perspectives from interested groups or statements about health, environmental, and animal welfare impacts.

In an extensive mail survey sent to households in Mid-Atlantic states during fall 2009, Onken et al. (2011) analyze consumer preferences and WTP for strawberry preserves with attributes for organic, "natural," locally-grown, and state marketing program promotions. 
Information was provided to households about organic and "natural" foods based on language from the NOP and FSIS' meat and poultry labeling terms, respectively. Among other results, they find evidence of higher marginal WTP for the "natural" attribute than the organic attribute. This could arise from consumer confusion of the two attributes. In a similar study, He and Bernard (2011) use fourth- and fifth-price auctions to analyze demand elasticities and premiums for conventional, non-GM, and organic sweet corn, potatoes, and tortilla/potato chips. The effects of subjects' demographics are mixed. The conventional foods tend to be most priceinelastic, while non-GM foods are most price-elastic, with subjects valuing organic over the nonGM attribute more in sweet corn than tortilla chips.

Most recently, Bazoche et al. (2014) and Meas et al. (2015) examine WTP and preferences for organic and related attributes in apples and blackberry jam. The former study uses an incentive-compatible mechanism to elicit WTP information in Portugal, France, Greece, and the Netherlands for apples produced conventionally, organically, and with reduced pesticides. They find that organic premiums increase after subjects receive information about organic production methods, though information has no impact on mean WTP for apples produced with integrated pest management practices. Meas et al. (2015) find a sizeable degree of overlapping values in WTP for blackberry jam with an organic and "local" attribute using statedpreference data.

\section{Experimental Design}

The use of random $n$ th-price auctions is a central component of our experimental design. We use this elicitation device, rather than the Becker et al. (1964) mechanism (BDM) or Vickrey (1961) auction, because of its frequent use in food values research and desirable properties in practice. The random $n$ th-price auction builds on the theoretical framework of the BDM 
mechanism and Vickrey auction. After participants bid on the experimental product, a random number, $n$, is drawn uniformly on $[2, k]$, where $k$ is the number of session participants. The bids are then ranked from highest to lowest. Those who bid higher than the $n$th bid are winners but pay the $n$th bid, not their submitted bid. As in other incentive compatible mechanisms, the bidders' dominant strategy is to truthfully reveal their valuations.

Shogren et al. (2001) argue that random $n$ th-price auctions are desirable because they engage "off-margin" bidders, i.e., low-value subjects still have a positive probability of winning. Using an experiment with induced values, the authors find more sincere bidding from low-value individuals in the random $n$ th-price auction than the Vickrey auction. A careful and thorough explanation of auction steps, combined with carefully answering subjects' questions, helps ensure a straightforward implementation with minimal potential for subject misconceptions.

\subsection{Background}

We performed the experiment on April 13, 2013 (Saturday) in a Midwestern city. The sessions began at 9:00 a.m., 11:30 a.m., and 2:00 p.m. There are two concurrent sessions at each starting time, so there are a total of six $(3 \times 2)$ sessions. The sample consists of 102 subjects.

The Survey and Behavioral Research Services (SBRS) at Iowa State University (ISU) developed the protocol for recruiting participants. A random sample of households was contacted to determine if there was at least one individual eligible to participate in group sessions in an ISU

project on food preferences. Recruiters were seeking adults aged 18-65 years who could follow directions, write in English, and participate on the experiment date. Contacted households were told that the sessions involve a food preference experiment set up like an auction or bidding 
activity, and they would be paid $\$ 65$ for about an hour of their time. ${ }^{3}$ Willing subjects were asked to pick among the three available starting times. They were told that there would be follow-up communication confirming time, location, and directions to the lab site. They started with a set of random telephone numbers. Willing subjects are allowed to suggest other family members and friends that would also be willing to participate.

We use the following commodities: fresh apples (Red Delicious, 3 lbs.), fresh eggs (Grade A large, one dozen), and fresh broccoli (1.25 lbs.). ${ }^{4}$ There are a diverse set of commodities because fresh produce comprises a large share of organic food sales, in addition to the experiment's high fixed costs and subjects' heterogeneous preferences. Each product has three types: conventional, "natural," and organic. "Natural" apples and broccoli were unavailable at local grocery stores, so we substituted for organic. ${ }^{5}$ This is acceptable since organic apples and broccoli meet any reasonable criterion for "natural" produce. The apples are displayed on a paper plate, the broccoli is displayed over a bed of ice on a paper plate, and the eggs are displayed in a standard carton with the top removed and without commercial logos.

The experiments offer two types of information: food labels and prepared information statements. Conventional products have a plain label that describes the product and its weight. "Natural" products have a label that describes the product and its weight, plus the words "AllNatural" printed in green ink. Organic products carry a similar product and weight description, plus the USDA's official organic seal in color. Figure 1 depicts the labels.

\footnotetext{
${ }^{3}$ We pay participants at the beginning of the sessions to separate the act of paying them for the work to be done in the experiment from the act of deciding how much to pay in the auctions. It also eliminates concerns about cash constraints (Huffman et al., 2003; Lusk and Shogren, 2007; Huffman et al., 2007; Bazoche et al., 2014).

${ }^{4} \mathrm{We}$ calculate that organic apples, eggs, and broccoli account for 4.3\%, 2.3\%, and 5.5\% of 2014 U.S. production and $8.6 \%, 5.4 \%$, and $9.6 \%$ of 2014 U.S. sales, respectively (USDA-NASS, 2016a; USDA-NASS, 2016b). Using Nielsen Homescan Data, Carlson and Jaenicke (2016) find that apples and eggs comprised $6.6 \%$ and $3.4 \%$ of 2010 U.S. sales. Data on market or production shares of "natural" foods are unavailable since "natural" does not have a widely-accepted, legally-binding definition.

${ }^{5}$ For the purposes of our experiment, we consider "natural" foods to be those with a claim on the foods' packaging indicating "all natural" or " $100 \%$ natural."
} 
Information treatments are constructed from four perspectives, each limited to one 8.5" $\mathrm{x}$ 11 " sheet of paper. These perspectives are (i). an organic food industry perspective on organic foods, (ii). independent, third-party, verifiable perspectives on organic foods, (iii). a "natural" food industry perspective on "natural" and "all natural" foods, and (iv). independent, third-party, verifiable perspective on "natural" foods. Each of these perspectives is organized under the same three headings (General Statement, Production Standards, and Nutrition, Taste, and Appearance; see Appendix) to assist subjects' reading and processing of information.

The information perspectives rely on information from nutrition research, government reports, non-governmental organization (NGO) reports, and websites. The "Production Standards" headings and organic and natural definitions draw on the NOP regulations and FSIS documentation (National Organic Program, 2002; USDA-FSIS, 2005). Much of the "natural" and organic food industry perspectives are adapted from statements on Whole Foods Market's website, and The Organic Center's website. The information perspectives were pretested and subsequently revised prior to implementation.

There are a total of five information treatments: (i). no-information baseline, (ii). "natural" food industry perspective only, (iii). "natural" food industry perspective plus independent, third-party, verifiable perspective on "natural" foods, (iv). organic food industry perspective, and (v). organic food industry perspective plus independent, third-party, verifiable perspective on organic foods. Each subject is randomly assigned one of the five information treatments in their packet with the protocol for the experiment. ${ }^{6}$

\footnotetext{
${ }^{6}$ No participant received a treatment consisting of three or four information perspectives or a combination of perspectives on both natural and organic foods. This reduces subject burden and session lengths.
} 
The design of the experiments introduces randomness at several levels. First, subjects are recruited randomly. ${ }^{7}$ Second, subjects are randomly assigned to a packet containing the protocol and information treatment. Third, they are alternately assigned to one of two concurrent sessions. Fourth, the order of bidding on products is randomized (e.g., we randomly select the order of conventional, "natural," and organic products). Fifth, we randomly select one of the three rounds of bidding as the binding round. This multilevel randomized design permits simple econometric identification by removing selection effects (Lusk and Shogren, 2007; Glennerster and Takavarasha, 2013).

\subsection{Subject Activities in a Session}

We now briefly review the steps of a typical auction session. Figure 2 is a flowchart of subject tasks. Participants read and sign an informed consent sheet upon arrival at the experimental site. After agreeing to participate, subjects are given an ID number and are randomly assigned to one of two concurrent sessions and a packet containing all materials necessary for participation. ${ }^{8}$ They are then instructed to begin completing the pre-auction questionnaire. Questions in the pre-auction questionnaire concern demographics, prior knowledge about "natural" and organic foods, frequency of looking at food labels when buying a new food product, and health. The demographics questions concern living in an urban/suburban/rural area, marital status, gender, age, household size, religion, number of children in certain age groups living in the household, level of schooling, ethnicity, household income, and occupation. The health questions include a Likert-scale question regarding overall health status and smoking status (at least once per day, less than once per day, or not at all). We

\footnotetext{
${ }^{7}$ We acknowledge that - as with most economics experiments - if a different sample were to be randomly drawn, then the empirical results could slightly differ.

${ }^{8}$ Individuals who arrive together (e.g., friends and family members) are placed in separate sessions, unless special circumstances require assignment to the same session. In this case, we ask that they do not sit next to each other, unless this is also necessary for extenuating reasons.
} 
distribute a $\$ 65$ participation fee and have subjects sign a receipt while they begin completing the pre-auction questionnaire.

Subjects are told to turn off electronic devices and not talk with others. After all subjects have completed the pre-auction questionnaire, session monitors tell subjects that they will be participating in an experimental auction and explain how the auction works. Subjects are notified that they can win at most one unit of each commodity. At this stage of the experiment, subjects are allowed and encouraged to ask clarifying questions. A brief quiz is administered to check understanding of the auction rules. We allow subjects four to five minutes to finish the quiz and then review the answers with additional explanation.

We then proceed to one of two practice rounds once any questions have been addressed. The first practice round trains subjects on the experimental auction methods, while the second practice round is designed to familiarize subjects with bidding on three commodities simultaneously. Following previous economics experiments, the commodity in the first practice round is a candy bar. Subjects are asked to come to the front of the room, view the candy bar, return to their seats, and write down bids. The session monitor and assistant then collect and rank the bids (in a spreadsheet), randomly draw the binding round, and determine the winner(s) via the auction rules. In the second practice round, subjects gain experience placing three bids at one time on a mug, deck of cards, and package of pens. Bids for the three products are sorted separately and displayed, and "winner" IDs are revealed. Unlike for winners in the binding round of the actual auctions, winners of the practice rounds are not required to purchase the practice goods. 
At the conclusion of the practice rounds, subjects are given approximately ten minutes to read their assigned information treatment. ${ }^{9}$ Subjects then bid on the three commodities, with the order (conventional, "natural," or organic) randomized across three distinct rounds of bidding. Bid sheets are collected, and the only posted bids are those for commodities in the binding round at the end of the auctions. ${ }^{10}$ Note that subjects are bidding on a separate set of products for each of the three rounds. However, the commodities across rounds are very similar and differ only with respect to labels and types (e.g., conventional, "natural," or organic).

In the final stage of a session, the binding round, random $n$, winning prices, and winning IDs are revealed. For product control purposes, we randomly choose the binding round and random $n$ prior to all sessions. After inputting bids for the binding round into a spreadsheet, the bids for all products are projected at the front of each session's room, and subjects watch the session monitor rank the bids and reveal winning IDs.

Subjects are then asked to complete a post-auction questionnaire. We ask participants about monthly purchases, weekly consumption, and household inventories of apples, eggs, and broccoli. Additional questions relate to prior awareness of organic food labels, sources of food product information, and the experiment's contribution to how informed subjects feel about organic and "natural" foods. Upon completion of the post-auction questionnaire, winners are directed to a stockroom to purchase the won item(s), and non-winners leave the experimental site.

\section{Econometric Model and Data}

\footnotetext{
${ }^{9}$ To ensure that outside information does not contaminate any specific treatment, session monitors and assistants do not answer questions related to informational content. To avoid confusion, we state that some subjects will have information to read, while others will not have information to read.

${ }^{10}$ Reference prices are not given for each of the products prior to bidding. Providing reference prices could bias subjects' WTP if they anchor on these prices as reference points, rather than truthfully revealing their maximal WTP. Bids are not posted because this could induce changes in bids in subsequent rounds (Corrigan and Rousu, 2006).
} 
The nature of the experiment and detailed questionnaire data permit latitude for empirical methods. Regression analysis of WTP levels, however, could be problematic. First, some zero bids are truncated at zero, i.e., subjects would have preferred to bid a negative value but felt constrained to bid zero instead. ${ }^{11}$ Other zero bids are legitimate bids with no truncation, i.e., zero was the preferred bid (Maddala, 1983). Second, valuation levels, although sincere, may be arbitrary (Ariely et al., 2003). Our approach uses WTP differences across subjects for parameter estimation. A major benefit of this method is that unobserved heterogeneity (e.g., subject fixed effects) are differenced

out in the estimation. Bids are pooled across commodities, with apples as the reference commodity.

\subsection{Regression Specification}

We propose the following pooled linear regression model of WTP differences:

$$
\begin{aligned}
& \operatorname{Bid}_{i}^{\text {Org }}-\operatorname{Bid}_{i}^{C o n}=\mathbf{X}_{\mathbf{i}}^{\prime} \boldsymbol{\beta}_{1}+\mathbf{T}_{\mathbf{i}}^{\prime} \mathbf{Y}_{\mathbf{1}}+\mathbf{C}_{j}+\varepsilon_{1, i} \\
& \operatorname{Bid}_{i}^{\text {Org }}-\operatorname{Bid}_{i}^{N a t}=\mathbf{X}_{\mathbf{i}}^{\prime} \boldsymbol{\beta}_{2}+\mathbf{T}_{\mathbf{i}}^{\prime} \mathbf{Y}_{2}+\mathbf{C}_{j}+\varepsilon_{2, i} \\
& \operatorname{Bid}_{i}^{N a t}-\operatorname{Bid}_{i}^{C o n}=\mathbf{X}_{\mathbf{i}}^{\prime} \boldsymbol{\beta}_{3}+\mathbf{T}_{\mathbf{i}}^{\prime} \mathbf{Y}_{3}+\mathbf{C}_{j}+\varepsilon_{3, i} .
\end{aligned}
$$

In the above equations, is the premium for organic products relative to conventional for the $i$ th bid. The premium for organic over "natural" is denoted, and the premium for "natural" over conventional is . Note that is a vector of controls on subjects' demographics, household food inventories, and previous knowledge about various labels and claims on food packaging. The indicator variables for information treatments are, and are fixed effects for . Estimates of the

\footnotetext{
${ }^{11}$ Few of the zero bids would be in cases where an individual would have preferred to bid less than zero but felt constrained to bid zero. Thus, the number of problem bids is very small, and a model taking into account censoring of WTP differences would not differ significantly from the reported results. Table A.1 in the appendix provides counts of the zero bids.
} 
are treatment effects. The error terms, , are assumed independent and identically-distributed (i.i.d) normal.

\subsection{Data}

Table 1 contains descriptive statistics for the set of nine bids across the sample. Several interesting trends are apparent. We find that subjects' valuations are increasing across product types (conventional, "natural," and organic) for all commodities. The difference in subjects' mean WTP for organic and conventional commodities is $\$ 0.54, \$ 0.57$, and $\$ 0.52$ for apples, eggs, and broccoli. As a percentage of the conventional price, subjects' organic premiums are $22 \%, 34 \%$, and 30\%, which are within the range in the literature (Park and Lohr, 1996; Bernard

et al., 2006; He and Bernard, 2011; Bazoche et al., 2014). Differences in mean WTP for organic and "natural" types are \$0.21 (7\%), \$0.30 (15\%), and \$0.27 (14\%) for apples, eggs, and broccoli. The "natural"-conventional differences in subjects' mean bids are \$0.33 (13\%), \$0.27 (16\%), and $\$ 0.25(14 \%)$. The raw data suggest that participants view "natural" products as intermediates (with respect to valuation) between conventionals and organics, similar to the progression of bids in Bernard et al. (2006), He and Bernard (2011), and Bazoche et al. (2014). "Natural" foods are imperfect substitutes for organic foods, but they are deemed more valuable than conventionals on average.

Variability in subjects' mean apple bids is consistent and relatively large across all commodity types. This is perhaps because of affinity for certain varieties of apples, either Red Delicious or another variety not represented in the experiment. Standard deviations for "natural" commodities are larger than conventional commodities, although standard deviations are quite similar for the set of "natural" and organic commodity bids. Given the lack of clear legal standards, participants may generally have varying interpretations of "natural" foods, which 
seem to be reflected in dispersed bidding. The opposite holds for conventional foods: an implicit designation as a reference or "status quo" food type may be contributing to subjects' greater uniformity of bids. Note that there is a low proportion of zero bids, with all bids strictly positive for organic eggs (see Table A.1 in the appendix).

Descriptive statistics for the variables used in regression analysis are displayed in Table 2. There are 273 useable bid observations after removing bids for which the subject's demographics data are missing. ${ }^{12}$ Statistics for subjects' food type premiums are broadly consistent with trends observed by commodity in Table 1. Mean premiums generally decrease from the $\$ 0.52$ organic-conventional difference to the $\$ 0.23$ "natural"-conventional difference. There is a small non-linearity in mean premiums with respect to "natural" foods. Subjects are willing to pay $\$ 0.29$ more for organic relative to "natural" commodities, but conventional products are worth $\$ 0.23$ less than "naturals," on average. Standard deviations are $\$ 0.60-\$ 0.65$, though there is some asymmetry in magnitudes between premiums and discounts. The largest organic-conventional premium $(\$ 2.80)$ for a subject is roughly twice the largest discount $(\$ 1.19)$. Such heterogeneity could have important marketing and segmentation implications.

The subjects have an average age of 43 years and have completed roughly 14 years of schooling (between a high school diploma and four-year college degree), and their households have an annual per-person income of $\$ 23,160 .{ }^{13}$ Women comprise $73 \%$ of the sample, approximating the trend that $57 \%$ of U.S. primary grocery store shoppers are women (FMI, 2014). Importantly, our pre-auction questionnaire elicits information that captures the non-linear impacts of number of children by age in a subject's household. Subjects on average have more

\footnotetext{
${ }^{12}$ A total of 33 bid observations are removed. Removal of these bids does not substantially affect the sign, magnitude, and statistical significance of the information treatment effects in the regression analysis.

${ }_{13}$ Annual per-capita incomes are calculated as the midpoint of the income bracket chosen by the respondent in the pre-auction questionnaire, divided by the number of people in the household.
} 
teenagers living at home than infants and toddlers, consistent with a higher frequency of older individuals in the sample. Subjects' households also have experience consuming and purchasing the experimental commodities. Roughly $77 \%, 82 \%$, and $48 \%$ of subjects had the three experimental products (apples, eggs, and broccoli) in their home food inventories at the time of the experiments.

There is also ample variation in participants' previous knowledge of "natural" and organic foods and past awareness of seals and labels. A little over half of the sample is at least somewhat informed about "natural" foods (55\%) and organic foods (59\%). Nearly $90 \%$ of subjects look at food labels at least some of the time when buying a new food product. Yet there is disparity in subjects having previously seen seals for "naturals" and organics. The USDA organic seal had been noticed by $66 \%$ of subjects in their shopping trips prior to the experiment, while only $14 \%$ had previously seen food product packaging with a claim of being $70 \%$ organic. This contrasts with high visibility for "natural"-labeled foods $(85 \%)$ and those made with "natural" ingredients $(80 \%) .{ }^{14}$ This might be indicative of the industry's relative advertising success to date.

Last, it should be pointed out that information treatments are randomly assigned in roughly uniform proportion. The organic industry perspective is assigned to $21 \%$ of the sample, while $16 \%$ of the sample receive both organic perspectives. The "natural" industry perspective is assigned to $19 \%$ of the sample, with both "natural" perspectives going to $20 \%$. The remaining $24 \%$ receive the no-information baseline treatment.

\section{Empirical Results and Discussion}

\subsection{Regression Analysis}

\footnotetext{
${ }^{14}$ Nearly all of the major supermarkets near the experiment site carry a broad assortment of organic foods. Further, a Whole Foods Market store is located 20 miles from the site. Thus, the summary statistics and regression results are not being influenced by inadequate access to organic foods.
} 
Table 3 presents regression results for the subjects' organic-conventional premiums. Of crucial interest are the information impacts. Somewhat surprisingly, we find that the organic food industry perspective or information does not significantly affect subjects' premiums over conventional foods. This could be because individuals who are very familiar with conventionally-produced foods may not think organic foods are necessary or bring many benefits, thus discounting positive information about organic foods (Gifford and Bernard, 2006). However, when combined with independent, third-party, verifiable information on organic foods, there is a $\$ 0.34$ decrease in subjects' premiums relative to those without information. This is consistent with recent studies that find significant effects of information or message framing on WTP or purchase intentions for organic foods (Gifford and Bernard, 2004; Gifford and Bernard, 2006; Rousseau and Vranken, 2013; Bazoche et al., 2014).

Information about "natural" foods has the opposite effect. The "natural" food industry perspective increases subjects' relative organic-conventional premium by $\$ 0.48$, whereas adding the independent information on "natural" foods is insignificant. The exact causes of these asymmetric effects cannot be identified in our study, but it is interesting that the results reflect current market characteristics. In recent years, consumers have had expanding access to both objective and subjective information about organics. Our results suggest that the net effect has reduced subjects' willingness to pay premiums, perhaps contributing to the organic industry's persistently small retail volumes. In the "natural" foods sector, there is much less access to independent information because of the lack of legal standards. It appears that greater WTP premiums for organic foods have increased as a result of a subject receiving and reading the "natural" food industry perspective. 
In contrast to prior studies that find few or no demographic impacts on WTP premiums, preferences, or purchase intentions of organic or GM foods (Huang, 1996; Huffman et al., 2003; Gifford and Bernard, 2004; Gifford and Bernard, 2006; Bazoche et al., 2014; Stzrok and Huffman, 2015), we find that subject demographics have broad effects. The premium is $\$ 0.24$ higher among women than for men, in line with most prior findings of significant gender effects (Govindasamy and Italia, 1999; He and Bernard, 2011; Bazoche et al., 2014). ${ }^{15}$ Older participants also have higher premiums, with an additional year increasing their premiums by one cent (evaluated at the sample mean), comparable to Misra et al. (1991) and Govindasamy and Italia (1999). Similarly, a marginal increase in subjects' household per-capita income $(\$ 1,000)$ increases the premium by one cent. Subjects' years of schooling are insignificant, which counters past research (Misra et al., 1991; Huang, 1996; Thompson and Kidwell, 1998; Bernard et al., 2006; Stzrok and Huffman, 2015), but supports the claim that the demographic landscape has become much broader.

Last, subjects' household inventories have some influence. Those with non-organic apples in home inventories have reduced premiums by $\$ 0.16$, and those with non-organic broccoli in home inventories have increased premiums of $\$ 0.37 .{ }^{16}$ The former finding is analogous to Govindasamy and Italia (1999), who find that regular purchasers of organic foods are $45 \%$ more likely to pay a $10 \%$ premium for organic foods relative to those who are not regular purchasers. Those with broccoli in home inventories are perhaps more nutritionallyconscious or concerned about eating fresh produce, for whom organics may be especially

\footnotetext{
${ }^{15}$ Govindasamy and Italia (1999) find that men are $12 \%$ less likely to pay a $10 \%$ premium for organic foods. He and Bernard (2011) find that the WTP ratio of organic to conventional potato and corn food products is 8-10\% lower for men. Bazoche et al. (2014) find that women are willing to pay $0.195 \mathrm{EUR} / \mathrm{kg}$ (roughly $\$ 0.21 /$ three pounds at time of their study) more than men for organic apples relative to conventional apples. However, Thompson and Kidwell (1998) and Bernard et al. (2006) generally find that gender is not statistically significant.

${ }^{16}$ Yue et al. (2009) find that the share of subjects willing to pay premiums for organic apples is reduced if the apples have cosmetic imperfections. Our results are robust to inclusion of dummy variables indicating subjects' perceptions of blemishes or discolorations in any of the commodities.
} 
appealing (Huang, 1996). It is also possible that frequency of organic food purchases could interact with information provision in determining WTP for organic foods (Rousseau and Vranken, 2013).

The regressions are also able to explain a likely source of conflicting evidence regarding the effects of household size and children on organic food values (Huang, 1996; He and Bernard, 2011; Bazoche et al., 2014). Our results suggest that subjects' households with more children in important developmental growth stages have higher valuations for organic over conventional foods. Subjects in households with an additional infant or toddler (0-3 years of age) are willing to pay $\$ 0.68$ more for organic relative to conventional commodities. This is a critical growth stage in very young children, and parents may feel encouraged to buy organic foods that are perceived to be healthier. Indeed, the organic baby food market has grown substantially in recent years, fueled by a willingness to pay premiums of $\$ 0.03-\$ 0.04$ per ounce (Maguire et al., 2004). Subjects' households with an additional child aged 8-12 years, the beginning of puberty for many children, have increased premiums of $\$ 0.19$. An extra child aged 4-7 years decreases subjects' premiums by $\$ 0.32$. This shows that a simple indicator of "young" or "teen" children in the household is inadequate for explaining the organic premium. Effects over differing age ranges must be considered for a more complete understanding of the relationship between children and parents' food preferences (Thompson and Kidwell, 1998).

Labels and previous food type information remain significant predictors of subjects' organic-conventional premiums (Aertsens et al., 2011). Subjects who regularly read labels have premiums that are $\$ 0.34$ higher than those who do not regularly read them. Those who read labels when buying new food products for the first time could be more nutritionally-conscious, which can translate into greater likelihood of purchasing organic foods and higher WTP (Huang, 
1996; Nielsen Company, 2015). Relative to subjects who were previously uninformed or who had not seen the official seal, organic premiums are $\$ 0.16-\$ 0.19$ higher. This is similar to Gifford and Bernard's (2004) finding that increased prior knowledge of organic methods increases the likelihood of purchasing organic foods in the future. The $70 \%$ organic and "natural" foods packaging claims do not significantly affect subjects' WTP.

The second column of Table 3 presents a reduced model that excludes several of the individually insignificant regressors. The $F$-statistic associated with testing that the coefficients on these regressors are jointly zero is 1.15 , less than the critical value of 1.57 at a $5 \%$ significance level. The estimated coefficients for the remaining variables are highly robust. It should also be emphasized that neither of the commodity fixed effects are significant, suggesting appropriateness of pooling the set of bids across commodities. The model fits well, with $38 \%$ of the premium variation explained by variation in treatment, demographics, and other predictors.

Regression results for subjects' organic-"natural" premiums are provided in Table 4. The focus is on coefficients in the reduced model of column (4), our preferred set of estimates. We cannot reject the null hypothesis that the set of deleted regressors are jointly equal to zero ( $F$ statistic of 1.25 compared to the critical value of 1.57 with a $5 \%$ significance level). The information effects are comparable to those from the analysis of subjects' organic-conventional premiums. It seems that the effect on subjects' WTP differences of independent organic information outweighs the effect of the organic food industry perspective, with a net negative effect of $\$ 0.27$ relative to those without information. The effect of the "natural" foods industry perspective on subjects' WTP differences is again positive and increases subjects' premiums by $\$ 0.41$ over those uninformed. This is similar in size and magnitude to the effect of information about organic methods on subjects' bids for organic apples (Bazoche et al., 2014). The addition 
of independent information on "natural" foods, however, decreases subjects' WTP differences by $\$ 0.20$. The general conclusion for subjects' organic-"natural" premiums is that adding independent information to biased food perspectives reduces excess valuations of organics over "naturals."

The impacts of subject demographics remain intuitive and comparable to those in Table 3. Women have $\$ 0.19$ higher organic-"natural" premiums than men. However, the marginal effect of a subject being older decreases the premium by one-half cent (evaluated at the sample mean), but the marginal effect of an extra year of age for a subject is positive beyond 46 years. ${ }^{17}$ An additional $\$ 1,000$ of per-capita income in a subject's household increases the premium by 1.6 cents at the sample mean, but additional per-capita income has negative effects beyond per-capita incomes of $\$ 39,000$, comparable to Govindasamy and Italia's (1999) finding that willingness to pay an organic premium is greater among households with annual incomes over $\$ 70,000$. Inventory effects are not as strong. Subjects that have conventional eggs in home inventories have $\$ 0.38$ lower organic-"natural" premiums. Subjects that have the most experience with conventional eggs could be unwilling to switch to "natural" or organic types, perhaps perceiving them as close substitutes, thus driving down the premium.

The advantages of estimating disaggregated family size effects on the organic-"natural" premiums are also clear. Additional children in a subject's household for all age groups except the post-toddler years (4-7 years of age) have positive effects on subjects' organic-"natural" premiums. The largest effects occur in the youngest and oldest age groups. It is not surprising that parents of very young children are willing to pay $\$ 0.25$ more for organic than conventional foods, given common perceptions that organic foods are healthier and contain lower

\footnotetext{
${ }^{17}$ The nonlinear relationship between subjects' age and WTP is not straightforward because older individuals could have dietary restrictions or be less inclined to change eating habits (Govindasamy and Italia, 1999).
} 
concentrations of pesticides (Maguire et al., 2006; Aertsens et al., 2011). However, increased premiums in subject households with more adult children are less straightforward to interpret. ${ }^{18}$ One potential explanation is that adult children in the household may have food preferences that are strongly influenced by peers or group membership (e.g., participation in student organic clubs or environmental organizations).

Last, we briefly mention that subjects' prior information and label awareness still help explain WTP differences, but the organic seal is no longer significant. Participants' prior information about organic foods raises the premium by $\$ 0.28$, and his or her awareness of the $70 \%$ organic claim has a similar $\$ 0.37$ impact. This could arise if those with greater prior awareness have more subjective knowledge or enhanced attitudes about organic foods (Aertsens et al., 2011), better opinions of organic foods (He and Bernard, 2011), or believe them to be "fairer" (Chang and Lusk, 2009), which could increase WTP. That the 70\% organic claim has more consequence than the USDA organic seal (at least 95\% organic) is puzzling, but Huffman and Stzrok (2015) report a similar outcome with respect to labels on food products of varying organic purity.

The final set of estimates in Table 5 reveal the difficult nature of making inference in markets with vague and distorted product claims. The reduced model in column (6) performs well (the coefficient of determination is $18 \%$ ), but there are fewer important indicators that explain participants' valuations for "natural" over conventional foods. If subjects conflate "natural" with "pesticide-free" or "produced with Integrated Pest Management (IPM) methods," then these results are comparable to those of other studies. Specifically, Misra et al. (1991) find that $54 \%$ of their sample are not willing to pay a higher price for certified pesticide-free produce,

\footnotetext{
${ }^{18}$ As pointed out by Maguire et al. (2006), perceived pesticide risks to children are made by third parties (e.g., parents or other caregivers), whose perceptions about health risks and safety for their children are heterogeneous and generally unclear to researchers.
} 
and Bazoche et al. (2014) find no evidence of information effects on mean WTP for IPMproduced apples. If subjects already have high trust in conventional foods (Gifford and Bernard, 2004), there would be less incentive to pay a premium for poorly-understood "natural" foods.

Of the information treatments, only the combined "natural" industry perspectives plus third-party perspective on "natural" foods has a significant non-zero effect. In this case, subjects have a premium of $\$ 0.32$ relative to those who do not receive information. Since biased information about "natural" foods is already prevalent in the marketplace, the $\$ 0.32$ represents a benefit to greater clarification. Subjects with a more balanced and objective understanding of "natural" foods may be increasingly willing to substitute conventional for "natural" foods.

Some of the key demographic effects on subjects' organic premiums are also present in their "natural" premiums. Subjects in households with an additional very young child will pay \$0.40 more for "natural" than conventional foods, though an opposite effect holds for those with 4-7 year-old children. There are similar impacts of a subject's household holding food inventories and of a subject reporting that she frequently reads food labels when purchasing new foods. Although the health or nutritional benefits accruing to "natural" foods are questionable, subjects who report having fresh broccoli in home food inventories and those who read food labels when purchasing new foods for the first time pay a premium of $\$ 0.30-\$ 0.49$ for "natural" foods. The remaining regressors have coefficients that are not significantly different from zero.

For ease of comparison, information effects on the three types of premiums are summarized graphically in Figure 3. These bar charts depict the point estimate of coefficients on the information treatment indicators for the reduced models (second columns) from Tables 3-5. Both organic food perspectives decrease subjects' organic-conventional premiums by $\$ 0.35$, and the "natural" foods industry perspective increases their premiums by $\$ 0.43$. Similarly, both 
organic foods perspectives decrease subjects' organic-“natural” premiums by $\$ 0.27$, while the "natural" foods industry perspective has a positive $\$ 0.41$ effect. Last, both "natural" foods perspectives have a combined $\$ 0.32$ effect on participants' "natural”-conventional premiums.

\subsection{The Value of Independent, Third-Party Information across Commodities}

We now calculate the expected value of independent, third-party information on the three experimental commodities using the methodology outlined in Rousu et al. (2007). The first step is to calculate the consumer surplus by subtracting the market price (e.g., grocery story price) of each commodity from each subject's commodity bids. ${ }^{19}$ Next, we assume that each subject purchases the particular version of each commodity (e.g., conventional, "natural," or organic) that yields the highest surplus. ${ }^{20}$ For subjects who received independent information, premium gains are then calculated as the (positive) difference in surpluses between organic and conventional commodities or organic and "natural" commodities.

We then calculate the net change in the percentage of subjects who purchase conventional commodities as a result of reading independent, third-party information. This is the absolute value of the difference between the percentage who purchase conventional when treated to independent information and the percentage who purchase conventional but not treated to independent information. We are interested in two cases: (i). subjects whose surpluses are largest for conventional and second-largest for "natural" commodities ("switchers from "natural" to conventional foods"), and (ii). subjects whose surpluses are largest for conventional and second largest for organic commodities ("switchers from organic to conventional foods"). For each of

\footnotetext{
${ }^{19}$ The market prices used in the calculations are the prices we paid for the foods in the experiment. Specifically, we paid $\$ 0.98 / \mathrm{lb}$ for conventional apples and $\$ 2.99 / \mathrm{lb}$ for organic apples. The conventional and organic broccoli prices are $\$ 2.49$ and $\$ 2.99$. The per-dozen conventional, "natural," and organic eggs' prices are $\$ 2.49, \$ 2.68$, and $\$ 4.18$, respectively. Since "natural" apples and broccoli were unavailable, we use the organic prices for these foods in the calculations underlying column 2 in Table 6.

${ }^{20}$ Several subjects had surpluses for "natural" commodities equal to their surpluses for organic commodities. These ties are resolved by assuming that the highest surplus is from conventional commodities and the lowest surplus from either "naturals" or organics, depending on the context.
} 
these cases, the first term in the difference is the fraction of subjects reading/receiving independent,

third-party information, and the second term is the fraction of subjects that did not receive independent, third-party information.

For each commodity, switching probabilities are then calculated as the percentage that switch divided by the percentage that buy (e.g., those whose surpluses are largest for conventional and second-largest for "natural" commodities, or those whose surpluses are largest for conventional and second-largest for organic commodities). Last, the expected value of information is the product of the switching probability and the mean premium gain. Interested readers are referred to Equations (5)-(13) of Rousu et al. (2007) for more information.

Table 6 provide estimates of the expected value of independent, third-party information for each of three commodities. In the first column of results, premium gains are calculated from the subsample of subjects who received either of the two "natural" information treatments, and whose surpluses were largest for conventional and then "natural" foods. In the second column of results, premium gains are calculated from the subsample of subjects who received either of the two organic information treatments, and whose surpluses were largest for conventional and then organic foods.

We find that the expected value of information for apples is largest at \$2.90-\$2.97 per three pounds. The expected value of information for broccoli, at $\$ 0.10-\$ 0.26$ per 1.25 pounds, is also moderately large and similar to value of information estimates for tortilla chips, vegetable oil, and potatoes (Rousu et al., 2007). Estimates for the dozen eggs are relatively small, a consequence of a smaller subsample size and fewer subjects switching. This suggests that independent, third-party information may have somewhat smaller impacts in the market for fresh 
eggs. This market has substantial variability in price premiums, and shoppers may be less willing to pay relatively high prices for certain kinds of eggs (Chang et al., 2010). In general, our results relate to those of Onken et al. (2011) who find that subjects in Mid-Atlantic states would need a price subsidy between $1 \%$ and $13.7 \%$ to switch from "natural" to organic strawberry preserves.

\subsection{Policy Implications for Natural and Organic Markets}

Real production costs of conventional U.S. agriculture have decreased over the past several decades. U.S. organic and "natural" food producers do not seem to have experienced similar cost reductions (Kuminoff and Wossink, 2010). This hinders the growth in U.S. production for these products, though imports can help meet increasing demand (Jaenicke et al., 2011). However, the current market structure continues to hinge on consumers willing to pay higher retail prices for organic foods (McBride et al., 2015) and "natural" foods.

Past industry studies and academic research have focused on identifying demographics of those willing to pay premiums in these niche markets. This has presumably motivated market segmentation strategies: retailers appeal to observable characteristics of shoppers who are likely to be purchasers. Such strategies have helped to increase the presence and market share of "natural" and organic foods. Yet our experimental results reflect the fundamental shift in national market structure towards a much broader customer base. We find a large and diverse set of subject demographic effects, consistent with the observation that the national market is in transition away from niche status. This is important since major U.S. food processors and national supermarkets have been recently attempting major development and/or expansions of organic product lines (Howard, 2009; Harris and Strom, 2014; Nassauer, 2016). Long-term contracts and agreements with producers may help capture economies of scale, lowering premiums and thus reinforcing expansion. 
Our finding of a cross-market asymmetric information effect, a kind of externality, has equally important implications. Subjects exposed to the "natural" food industry perspective are willing to pay $\$ 0.41-\$ 0.43$ more for organic foods, whereas information about organic foods has no impact on their premiums for "natural" over conventional foods. It seems that the "natural" food industry could benefit from more objective information and meaningful labels. Organic markets have benefited from low-quality "natural" food information and vague labels, perhaps prompting some consumers to switch from "natural" to organic products. Some consumers have brought about class action lawsuits alleging deceptive business practices by "natural" food retailers (Benny, 2012; Negowetti, 2013; Thompson, 2014). Several of these suits have been filed by the Center for Science in the Public Interest in courts in California, a state with strong consumer protection laws, general support of organic agriculture, and aversion to GM foods in some counties. One potentially effective but costly method of reducing misinformation and deception is the development, implementation, and enforcement of a binding legal standard. However, the general welfare effects of such a standard are currently unclear.

Participants who regularly read organic labels pay relatively more for organic foods than those who do not. Although we find no effects from subjects' prior awareness of "natural" food labels, those who regularly read food labels when purchasing a new food item are willing to pay more for both organic and "natural" foods relative to conventional ones. Meaningful food labels, such as the USDA organic seal, can contribute to more effective information flow by summarizing relevant attributes of certified production processes. In effect, labels help ensure trust in credence goods without exhaustively listing all production practices.

In well-functioning markets, voluntary labeling might be expected to occur if demanded by a majority of market participants. For example, some private organizations have enacted 
independent certification procedures permitting foods to carry a "non-GM" seal if they meet voluntary standards and pass verification tests (Non-GMO Project, 2016). In contrast to these voluntary labeling efforts, a national bioengineered food disclosure standard was enacted in July, 2016 (Public Law 114-216, 2016). It supersedes all state GM labeling legislation. If the FDA establishes a legal definition or standard for the term "natural" in food labeling (US-HHS-FDA, 2015) and the USDA establishes a verification system, this could have the potential to clear up the currently confusing "natural" designations.

\section{Conclusion}

U.S. demand for "natural" and organic foods have increased substantially in recent decades. This stems from renewed and increasing interest in nutrition, public health, animal welfare, and the environmental impacts of conventional agriculture. A general understanding of these diverse topics is complicated by a mix of labels and distorted claims. Conclusions from independent academic research about these foods are often at odds with arguments employed by private interest groups and trade associations. Food labels offer a similar dichotomy: certain seals like the USDA organic seal are a credible signal that the food product meets the NOP's standards. Foods with "natural" labels do not have an underlying binding legal standard. These foods are not made with uniform and certified production practices across farms and processors, and can contain ingredients that most consumers consider to be unnatural.

Our experimental design and results offer opportunities for future research. Although we can estimate the impact and value of third-party information by comparing treatments effects among subjects who receive both perspectives to those who receive only industry perspectives, 
another design approach would have been to randomly assign third-party perspectives only, in addition to the other randomly-assigned information treatments. However, a larger sample size would be required for identification of these two additional treatment effects. Moreover, a small set of food items display both the USDA organic seal and "natural" claims (e.g., eggs and processed snack foods). An experimental design that includes bidding on a fourth set of food items with both packaging claims would be an interesting and useful contribution, despite the potential increase in session length and experiment complexity

Nevertheless, the results have broad policy implications for "natural" and organic retail markets and contribute to the ongoing discussion of the role of information and voluntary food labeling. First, subjects' organic food premiums (relative to both "natural" and conventional foods) tend to increase as a result of information favoring "natural" foods, but industry and independent, third-party perspectives on organic foods have no effect on subjects' "natural" food premiums. Pairing an independent, third-party perspective about organic foods with an organic industry perspective reduces both types of organic premiums. These findings imply greater scope for objective information to help dispel persistent misconceptions about the nutrition, taste, and environmental benefits of organic foods, but especially those surrounding "natural" foods. Second, our results suggest a demographic widening of demand. Retailers and other suppliers could potentially increase sales with more general advertising. However, subjects' demand (and likely price elasticities) varies by age of children in the household, implying a potential for additional segmentation strategies. Third, subjects' prior knowledge of organic foods and labeling influence their premiums, notably among those who actively read food labels when purchasing new foods. Higher-quality information, especially about "natural" foods, would promote greater effectiveness of labels. Misinformation about "natural" foods could be 
substantially eliminated through objective information campaigns (e.g., public service announcements), public-sector guidance for industry, and/or the development and enforcement of a legally-binding standard. 


\section{References}

Aertsens J, Mondelaers K, Verbeke W, Buysse J, and Van Huylenbroeck G. 2011. The influence of subjective and objective knowledge on attitude, motivations and consumption of organic food. British Food Journal 113(11): 1353-1378.

Anstine J. 2007. Organic and all natural: do consumers know the difference? Journal of Applied Economics \& Policy 26(1): 15-27.

Ariely D, Loewenstein G, and Prelec D. 2003. Coherent arbitrariness: stable demand curves without stable preferences. Quarterly Journal of Economics 118(1):73-106.

Batte MT, Hooker NH, Haab TC, and Beaverson J. 2007. Putting their money where their mouths are: consumer willingness to pay for multi-ingredient, processed organic food products. Food Policy 32(2): 145-159.

Bazoche P, Combris P, Giraud-Héraud E, Pinto AS, Bunte F, and Tsakiridou, E. 2014. Willingness to pay for pesticide reduction in the EU: nothing but organic? European Review of Agricultural Economics 41(1): 87-109.

Becker G, DeGroot M, and Marschak J. 1964. Measuring utility by a single-response sequential method. Behavioral Science 9(3): 226-232.

Benny E. 2012. "Natural" Modifications: The FDA's need to promulgate an official definition of "natural" that includes genetically modified organisms. The George Washington Law Review 80(5): 1504-1526.

Bernard JC, Zhang C, and Gifford K. 2006. An experimental investigation of consumer willingness to pay for non-GM foods when an organic option is present. Agricultural and Resource Economics Review 35(2): 374-385.

Bernard JC and Bernard DJ. 2009. What is it about organic milk? An experimental analysis. American Journal of Agricultural Economics 91(3): 826-836.

Bernard JC and Bernard DJ. 2010. Comparing parts with the whole: willingness to pay for pesticide-free, non-GM, and organic potatoes and sweet corn. Journal of Agricultural and Resource Economics 35(3): 457-475.

Carlson A and Jaenicke E. 2016. Changes in retail organic price premiums from 2004 to 2010. Economic Research Report No. 209. United States Department of Agriculture, Economic Research Service.

Chang JB and Lusk JL. 2009. Fairness and food choice. Food Policy 34(6): 483-491.

Chang JB, Lusk JL, and Norwood FB. 2010. The price of happy hens: a hedonic analysis of retail egg prices. Journal of Agricultural and Resource Economics 35(3): 406-423. 
Corrigan JR and Rousu MC. 2006. Posted prices and bid affiliation: evidence from experimental auctions. American Journal of Agricultural Economics 88(4): 1078-1090.

Dettmann RL and Dimitri C. 2009. Who's buying organic vegetables? Demographic characteristics of U.S. consumers. Journal of Food Products Marketing 16(1): 79-91.

Dimitri C and Dettmann RL. 2012. Organic food consumers: what do we really know about them? British Food Journal 114(8): 1157-1183.

FMI. 2014. U.S. grocery shopper trends 2014. Report. Food Marketing Institute.

Gifford K and Bernard JC. 2004. The impact of message framing on organic food purchase likelihood. Journal of Food Distribution Research 35(3): 19-28.

Gifford K and Bernard JC. 2006. Influencing consumer purchase likelihood of organic food. International Journal of Consumer Studies 30(2): 155-163.

Gifford K and Bernard JC. 2011. The effect of information on consumers' willingness to pay for natural and organic chicken. International Journal of Consumer Studies 35(3): 282-289.

Glennerster R and Takavarasha K. 2013. Running randomized evaluations: a practical guide. Princeton University Press: Princeton, NJ.

Govindasamy R and Italia J. 1991. Predicting willingness-to-pay a premium for organically grown fresh produce. Journal of Food Distribution Research 30(July): 44-53.

Greene C, Dimitri C, Lin BH, McBride W, Oberholtzer L, and Smith T. 2009. "Emerging issues in the U.S. organic industry." Economic Information Bulletin No. 55. United States Department of Agriculture, Economic Research Service.

Hamilton SF and Zilberman D. 2006. Green markets, eco-certification, and equilibrium fraud. Journal of Environmental Economics and Management 52(3): 627-644.

Harris EA and Strom S. 2014. "Walmart to sell organic food, undercutting big brands." The New York Times: B9.

He N and Bernard JC. 2011. Differences in WTP and consumer demand for organic and nonGM fresh and processed foods. Agricultural and Resource Economics Review 40(2): 218-232.

Howard PH. 2009. Organic industry structure. Media-N: Journal of the New Media Caucus 5(3).

Huang CL. 1996. Consumer preferences and attitudes towards organically grown produce. European Review of Agricultural Economics 23(3): 331-342. 
Huang CL and Lin B-H. 2007. A hedonic analysis of fresh tomato prices among regional markets. Review of Agricultural Economics 29(4): 783-800.

Huffman WE, Shogren JF, Rousu M, and Tegene A. 2003. Consumer willingness to pay for genetically modified food labels in a market with diverse information: evidence from experimental auctions. Journal of Agricultural and Resource Economics 28(3): 481-502.

Huffman WE, Rousu M, Shogren JF, and Tegene A. 2007. The effects of prior beliefs and learning on consumers acceptance of genetically modified foods. Journal of Economic Behavior and Organization 63(1): 193-206.

Jaenicke E, Dimitri C, and Oberholtzer L. 2011. Retailer decisions about organic imports and organic private labels. American Journal of Agricultural Economics 93(2): 597-603.

Jolly DA, Schultz HGK, Diaz-Knauf V, and Johal J. 1989. Organic foods: consumer attitudes and use. Food Technology 43(11): 60-66.

Klonsky K. 2012. Comparison of production costs and resource use for organic and conventional production systems. American Journal of Agricultural Economics 94(2): 314-321.

Kuminoff NV and Wossink A. 2010. Why isn't more US farmland organic? Journal of Agricultural Economics 61(2): 240-258.

Lin B-H, Smith TA, and Huang CL. 2008. Organic premiums of U.S. fresh produce. Renewable Agriculture and Food Systems 23(3): 208-216.

Lin B-H, Yen ST, Huang CL, and Smith TA. 2009. U.S. demand for organic and conventional fresh fruits: the roles of income and price. Sustainability 1(3): 464-478.

Lusk JL and Shogren JF. 2007. Experimental auctions: methods and applications in economic and marketing research. Cambridge University Press: Cambridge, UK.

Maddala G. 1983. Limited dependent and qualitative variables in econometrics. Vol. 3. Econometric society monographs in quantitative economics. Cambridge University Press: Cambridge, UK.

Maguire KB, Owens N, and Simon NB. 2004. The price premium for organic babyfood: a hedonic analysis. Journal of Agricultural and Resource Economics 29(1): 132-149.

Maguire KB, Owens N, and Simon NB. 2006. Focus on babies: a note on parental attitudes and preferences for organic babyfood. Journal of Agribusiness 24(2): 187-195.

McBride WD, Greene C, Foreman L, and Ali M. 2015. "The profit potential of certified organic field crop production." Economic Research Report No. 188. United States Department of Agriculture, Economic Research Service. 
Meas T, Hu W, Batte MT, Woods TA, and Ernst S. 2015. Substitutes or complements? Consumer preference for local and organic food attributes. American Journal of Agricultural Economics 97(4): 1044-1071.

Menkhaus DJ, Borden GW, Whipple GD, Hoffman E, and Field RA. 1992. An empirical application of experimental economics in marketing research. Journal of Agricultural and Resource Economics 17(1): 44-55.

Milgrom P and Roberts J. 1986. Relying on the information of interested parties. The RAND Journal of Economics 17(1): 18-32.

Misra SK, Huang CL, and Ott SL. 1991. Consumer willingness to pay for pesticide-free fresh produce. Western Journal of Agricultural Economics 16(2): 218-227.

Nassauer S. 2016. "Wal-Mart to Drop Wild Oats Organic Food Brand." The Wall Street Journal. Business Section.

National Organic Program. 2002. "Organic production and handling requirements." 7 CFR Part 205.

Negowetti NE. 2013. A national "natural" standard for food labeling. Maine Law Review 65(2): 581-604.

Nielsen Company. 2015. We are what we eat: healthy eating trends around the world. Report. January, 2015.

Non-GMO Project. 2016. "Non-GMO project standard.” Version 13. Website. URL: < http://www.nongmoproject.org/wp-content/uploads/Non-GMO-ProjectStandard.pdf $>$ (accessed 5-14-2016).

Onken KA, Bernard JC, and Pesek Jr., John D. 2011. Comparing willingness to pay for organic, natural, locally grown, and state marketing program promoted foods in the midAtlantic region. Agricultural and Resource Economics Review 40(1): 33-47.

Organic Trade Association. 2016. U.S. organic sales post new record of \$43.3 billion in 2015. Press Release. May, 2016.

Park TA and Lohr L. 1996. Supply and demand factors for organic produce. American Journal of Agricultural Economics 78(3): 647-655.

Public Law 114-216. 2016. An Act to reauthorize and amend the National Sea Grant College Program Act, and for other purposes. "National Bioengineered Food Disclosure Standard.” 130 Stat. 834. July 29, 2016. 
Roosen J, Fox JA, Hennessy DA, and Schreiber A. 1998. Consumers' valuation of insecticide use restrictions: an application to apples. Journal of Agricultural and Resource Economics 23(2): 367-384.

Rousseau S and Vranken L. 2013. Green market expansion by reducing information asymmetries: Evidence for labeled organic food products. Food Policy 40: 31-43.

Rousu M, Huffman WE, Shogren JF, and Tegene A. 2007. Effects and value of verifiable information in a controversial market: evidence from lab auctions of genetically modified food. Economic Inquiry 45(3): 409-432.

Shogren J, Margolis M, Koo C, and List J. 2001. A random nth-price auction. Journal of Economic Behavior and Organization 46(4): 409-421.

Smith TA, Huang CL, and Lin B-H. 2009. Estimating organic premiums in the U.S. fluid milk' market. Renewable Agriculture and Food Systems 24(3): 197-204.

Stzrok JL and Huffman WE. 2015. Willingness to pay for organic food products and organic purity: experimental evidence. AgBioForum 18(3): 345-353.

Thompson GD. 1998. Consumer demand for organic foods: what we know and what we need to know. American Journal of Agricultural Economics 80(5): 1113-1118.

Thompson GD and Kidwell J. 1998. Explaining the choice of organic produce: cosmetic defects, prices, and consumer preferences. American Journal of Agricultural Economics 80(2): 277-287.

Thompson S. 2014. Artificially "natural": class action lawsuits attack misleading "natural" claims in FDA's absence. Indiana Law Review 47(3): 893-918.

USDA-ERS. 2016. “Organic market overview.” Website. URL: < http://www.ers.usda.gov/topics/natural-resources-environment/organicagriculture/organic-market-overview.aspx $>$ (accessed 5-14-2016).

USDA-FSIS. 2005. Food standards and labeling policy book. Report. United States Department of Agriculture, Food Safety and Inspection Service.

USDA-NASS. 2010. Organic production survey (2008). Volume 3, special studies, part 2. United States Department of Agriculture, National Agricultural Statistics Service.

USDA-NASS. 2012. 2011 Certified organic production survey. Report. United States Department of Agriculture, National Agricultural Statistics Service.

USDA-NASS. 2016a. Organic survey (2014). Volume 3, special studies, part 4. United States Department of Agriculture, National Agricultural Statistics Service. 
USDA-NASS. 2016b. “Quick Stats 2.0” Website. URL: < https://quickstats.nass.usda.gov > (accessed 5-14-2016).

US-HHS-FDA. 1991. "Food labeling: nutrient content claims, general principles, petitions, definitions of terms." 56 Fed. Reg. 60,421, 60,466. United States Department of Health and Human Services, Food and Drug Administration.

US-HHS-FDA. 2015. "Use of the term "natural" in the labelling of human food products; request for information and comments." 80 Fed. Reg. 69,905, 69,909. United States Department of Health and Human Services, Food and Drug Administration.

Vickrey WS. 1961. Counterspeculation, auctions, and competitive sealed tenders. The Journal of Finance 16(1): 8-37.

Yue C, Alfnes F, and Jensen HH. 2009. Discounting spotted apples: investigating consumers' willingness to accept cosmetic damage in an organic product. Journal of Agricultural and Applied Economics 41(1): 29-46.

Zhang F, Huang CL, Lin B-H, and Epperson JE. 2008. Modeling fresh organic produce consumption with scanner data: a generalized double hurdle model Approach. Agribusiness 24(4): 510-522. 

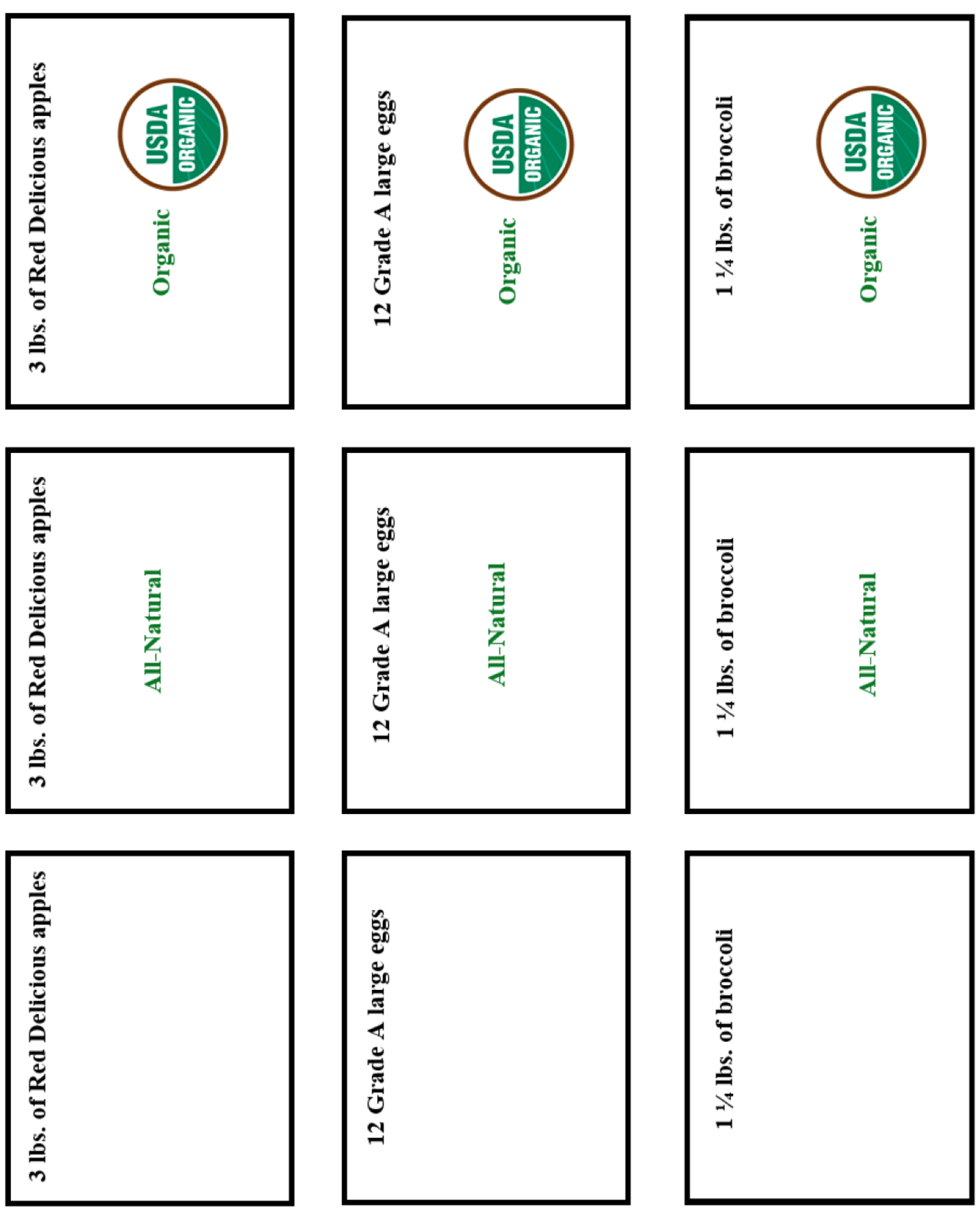

Fig. 1. Commodity labels for apples, eggs, and broccoli. 


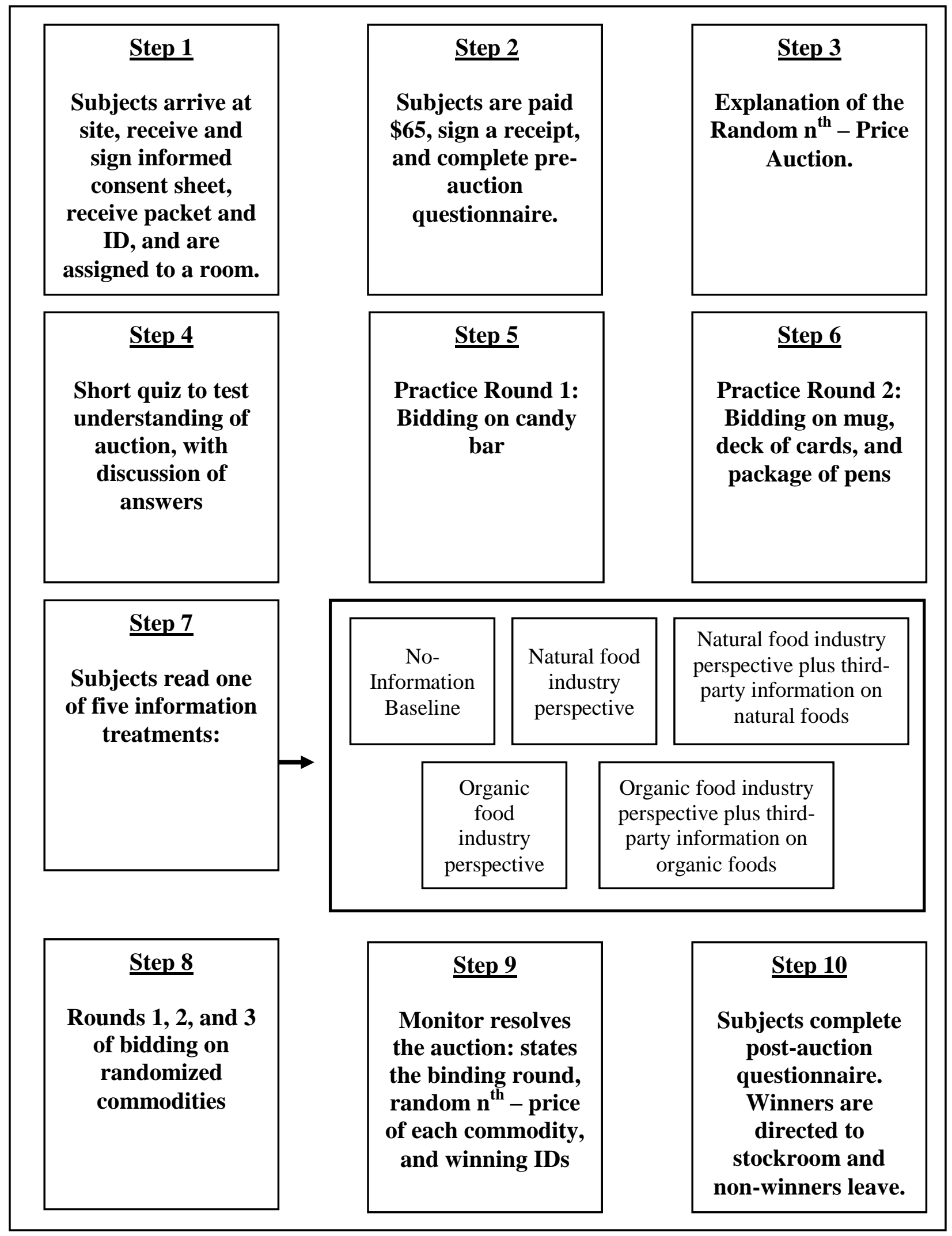

Fig. 2. Subject activities in a session. 
Table 1. Consumer WTP levels: commodities by type $(N=102)$.

\begin{tabular}{lcccc}
\hline \multicolumn{1}{c}{ Bid (\$) } & Mean & Std. Dev. & Min & Max \\
\hline Conventional Commodities & & & & \\
Apples & 2.51 & 1.21 & 0.00 & 6.75 \\
Eggs & 1.67 & 0.75 & 0.00 & 4.00 \\
Broccoli & 1.74 & 0.87 & 0.00 & 4.00 \\
& & & & \\
Natural Commodities & & & & \\
Apples & 2.84 & 1.58 & 0.00 & 9.00 \\
Eggs & 1.94 & 1.00 & 0.00 & 6.00 \\
Broccoli & 1.99 & 1.07 & 0.00 & 6.00 \\
& & & & \\
Organic Commodities & & & & \\
Apples & 3.05 & 1.58 & 0.00 & 7.80 \\
Eggs & 2.24 & 1.00 & 0.25 & 6.00 \\
Broccoli & 2.26 & 1.07 & 0.00 & 5.25 \\
\hline
\end{tabular}


Table 2. Summary statistics: bid differences and regressors $(N=273)$.

\begin{tabular}{|c|c|c|c|c|}
\hline Variable & Mean & Std. Dev. & Min & Max \\
\hline \multicolumn{5}{|l|}{ Dependent Variable (\$) } \\
\hline Org Commodity Bid - Con Commodity Bid & 0.52 & 0.65 & -1.19 & 2.80 \\
\hline Org Commodity Bid - Nat Commodity Bid & 0.29 & 0.60 & -2.15 & 2.61 \\
\hline Nat Commodity Bid - Con Commodity Bid & 0.23 & 0.62 & -1.25 & 4.15 \\
\hline \multicolumn{5}{|l|}{ General Demographics } \\
\hline Female $(0-1)$ & 0.73 & 0.45 & 0 & 1 \\
\hline Age (integer) & 43.04 & 11.48 & 22 & 65 \\
\hline $\operatorname{Age}^{2}$ (integer) & $1,983.99$ & $1,001.00$ & 484 & 4,225 \\
\hline Years of schooling (integer) & 14.22 & 2.20 & 10 & 22 \\
\hline Per capita income ( $\$ 1000 \mathrm{~s})$ & 23.16 & 15.75 & 1 & 68.75 \\
\hline Per capita income ${ }^{2}(\$ 1000 s)$ & 783.50 & 993.15 & 1 & $4,726.56$ \\
\hline Children aged $0-3$ years in household (integer) & 0.13 & 0.34 & 0 & 1 \\
\hline Children aged 4-7 years in household (integer) & 0.21 & 0.48 & 0 & 2 \\
\hline Children aged 8-12 years in household (integer) & 0.27 & 0.58 & 0 & 2 \\
\hline Children aged 13-18 years in household (integer) & 0.33 & 0.67 & 0 & 3 \\
\hline Children older than 18 years in household (integer) & 0.36 & 0.78 & 0 & 4 \\
\hline Previously informed about organic foods $(0-1)$ & 0.59 & 0.49 & 0 & 1 \\
\hline Previously informed about natural foods $(0-1)$ & 0.55 & 0.50 & 0 & 1 \\
\hline \multicolumn{5}{|l|}{ Household Inventories (0-1) } \\
\hline Conventional or natural apples at home & 0.77 & 0.42 & 0 & 1 \\
\hline Conventional eggs at home & 0.82 & 0.38 & 0 & 1 \\
\hline Conventional or natural broccoli at home & 0.48 & 0.50 & 0 & 1 \\
\hline \multicolumn{5}{|l|}{ Labeling and Food Product Claims (0-1) } \\
\hline Looks at labels when buying new foods & 0.89 & 0.31 & 0 & 1 \\
\hline Previously seen USDA organic seal & 0.66 & 0.47 & 0 & 1 \\
\hline Previously seen natural claim & 0.85 & 0.36 & 0 & 1 \\
\hline Previously seen $70 \%$ organic claim & 0.14 & 0.35 & 0 & 1 \\
\hline Previously seen "Made with Natural Ingredients" & 0.80 & 0.40 & 0 & 1 \\
\hline \multicolumn{5}{|l|}{ Commodity Bid Indicator (0-1) } \\
\hline Eggs & 0.33 & 0.47 & 0 & 1 \\
\hline Broccoli & 0.33 & 0.47 & 0 & 1 \\
\hline \multicolumn{5}{|l|}{ Information Treatments $(0-1)$} \\
\hline Organic Industry & 0.21 & 0.41 & 0 & 1 \\
\hline Organic Industry and Independent Organic & 0.16 & 0.37 & 0 & 1 \\
\hline Natural Industry & 0.19 & 0.39 & 0 & 1 \\
\hline Natural Industry and Independent Natural & 0.20 & 0.40 & 0 & 1 \\
\hline
\end{tabular}


Table 3. Organic-conventional WTP differences.

\begin{tabular}{|c|c|c|}
\hline & (1) & (2) \\
\hline Organic Industry information & 0.039 & 0.043 \\
\hline Organic Industry and Independent Organic information & $-0.335^{* * * *}$ & $-0.347^{* * *}$ \\
\hline Natural Industry information & $0.483^{* * *}$ & $0.430^{* * *}$ \\
\hline Natural Industry and Independent Organic information & 0.138 & 0.131 \\
\hline Female & $0.236^{* * * *}$ & $0.243^{* * *}$ \\
\hline Age & $-0.076^{* * * *}$ & $-0.072^{* * *}$ \\
\hline $\mathrm{Age}^{2}$ & $0.001^{* * *}$ & $0.001^{* * *}$ \\
\hline Years of schooling & -0.020 & \\
\hline Per capita income & $0.029^{* * * *}$ & $0.027^{* * *}$ \\
\hline Per capita income ${ }^{2}$ & $-0.0004^{* * * *}$ & $-0.0004^{* * *}$ \\
\hline Children aged $0-3$ years in household & $0.680^{* * * *}$ & $0.688^{* * * *}$ \\
\hline Children aged 4-7 years in household & $-0.316^{* * * *}$ & $-0.350^{* * * *}$ \\
\hline Children aged 8-12 years in household & $0.190^{* * * *}$ & $0.185^{* *}$ \\
\hline Children aged $13-18$ years in household & 0.091 & 0.072 \\
\hline Children older than 18 years in household & 0.098 & 0.070 \\
\hline Conventional or natural apples at home & $-0.160^{*}$ & $-0.201^{* * *}$ \\
\hline Conventional eggs at home & $-0.180^{*}$ & -0.119 \\
\hline Conventional or natural broccoli at home & $0.366^{* * * *}$ & $0.370^{* * *}$ \\
\hline Looks at labels when buying new foods & $0.338^{* * *}$ & $0.350^{* * * *}$ \\
\hline Previously informed about organic foods & $0.164^{*}$ & 0.119 \\
\hline Previously informed about natural foods & -0.035 & \\
\hline Previously seen USDA organic seal & $0.172^{*}$ & $0.192^{* *}$ \\
\hline Previously seen natural claim & -0.029 & -0.016 \\
\hline Previously seen $70 \%$ organic claim & 0.175 & \\
\hline Previously seen "Made with Natural Ingredients" & -0.072 & -0.064 \\
\hline Broccoli & -0.073 & -0.073 \\
\hline Eggs & -0.009 & -0.009 \\
\hline Constant & $1.276^{* * *}$ & $0.922^{*}$ \\
\hline Observations & 273 & 273 \\
\hline$R^{2}$ & 0.385 & 0.376 \\
\hline$F$-statistic & $5.670^{* * * *}$ & $6.224^{* * * *}$ \\
\hline
\end{tabular}

Note: Significance is denoted as $*(\mathrm{p}<0.1), * *(\mathrm{p}<0.05), * * *(\mathrm{p}<0.01)$. Dependent variable in columns $(1)$ and $(2)$ is the WTP for conventional commodities subtracted from the WTP for organic commodities. The $F$-statistic for testing the null hypothesis that the coefficients on the regressors deleted in column (2) are jointly zero is 1.15 , with a p-value of 0.33 . 
Table 4. Organic-natural WTP differences.

\begin{tabular}{|c|c|c|}
\hline & (3) & (4) \\
\hline Organic Industry information & -0.021 & -0.030 \\
\hline Organic Industry and Independent Organic information & $-0.264^{* *}$ & $-0.266^{* *}$ \\
\hline Natural Industry information & $0.403^{\text {**** }}$ & $0.409^{* * *}$ \\
\hline Natural Industry and Independent Organic information & $-0.179^{*}$ & $-0.195^{*}$ \\
\hline Female & $0.164^{* *}$ & $0.186^{* * *}$ \\
\hline Age & $-0.096^{* * * *}$ & $-0.092^{* * * *}$ \\
\hline $\mathrm{Age}^{2}$ & $0.001^{* * *}$ & $0.001^{* * *}$ \\
\hline Years of schooling & -0.011 & \\
\hline Per capita income & $0.039^{* * *}$ & $0.039^{* * *}$ \\
\hline Per capita income ${ }^{2}$ & $-0.0005^{* * *}$ & $-0.0005^{* * *}$ \\
\hline Children aged $0-3$ years in household & $0.241^{* *}$ & $0.254^{* *}$ \\
\hline Children aged 4-7 years in household & -0.075 & -0.076 \\
\hline Children aged 8-12 years in household & $0.179^{* *}$ & $0.162^{* *}$ \\
\hline Children aged $13-18$ years in household & $0.137^{* *}$ & $0.119^{* * *}$ \\
\hline Children older than 18 years in household & $0.266^{* * *}$ & $0.265^{* * *}$ \\
\hline Conventional or natural apples at home & -0.077 & -0.057 \\
\hline Conventional eggs at home & $-0.405^{* * *}$ & $-0.379^{* * *}$ \\
\hline Conventional or natural broccoli at home & 0.048 & 0.046 \\
\hline Looks at labels when buying new foods & -0.147 & -0.158 \\
\hline Previously informed about organic foods & $0.340^{* * *}$ & $0.279^{* * *}$ \\
\hline Previously informed about natural foods & -0.108 & \\
\hline Previously seen USDA organic seal & 0.118 & \\
\hline Previously seen natural claim & 0.040 & 0.096 \\
\hline Previously seen $70 \%$ organic claim & $0.360^{* * *}$ & $0.366^{* * *}$ \\
\hline Previously seen "Made with Natural Ingredients" & 0.092 & 0.074 \\
\hline Broccoli & -0.024 & -0.024 \\
\hline Eggs & 0.037 & 0.037 \\
\hline Constant & $1.914^{* * *}$ & $1.672^{* * * *}$ \\
\hline Observations & 273 & 273 \\
\hline$R^{2}$ & 0.336 & 0.325 \\
\hline$F$-statistic & $4.583^{* * *}$ & $4.985^{* * * *}$ \\
\hline
\end{tabular}

Note: Significance is denoted as $*(\mathrm{p}<0.1), * *(\mathrm{p}<0.05), * * *(\mathrm{p}<0.01)$. Dependent variable in columns $(3)$ and $(4)$ is the WTP for natural commodities subtracted from the WTP for organic commodities. The $F$-statistic for testing the null hypothesis that the coefficients on the regressors deleted in column (4) are jointly zero is 1.25 , with a pvalue of 0.29 . 
Table 5. Natural-conventional WTP differences.

\begin{tabular}{|c|c|c|}
\hline & (5) & $(6)$ \\
\hline Organic Industry information & -0.059 & 0.096 \\
\hline Organic Industry and Independent Organic information & -0.071 & -0.033 \\
\hline Natural Industry information & 0.080 & 0.190 \\
\hline Natural Industry and Independent Organic information & $0.317^{* * * *}$ & $0.324^{\text {**** }}$ \\
\hline Female & 0.072 & \\
\hline Age & 0.020 & \\
\hline $\mathrm{Age}^{2}$ & -0.0001 & \\
\hline Years of schooling & -0.009 & \\
\hline Per capita income & -0.010 & \\
\hline Per capita income ${ }^{2}$ & 0.0001 & \\
\hline Children aged $0-3$ years in household & $0.439^{* * * *}$ & $0.400^{* * * *}$ \\
\hline Children aged $4-7$ years in household & $-0.242^{* * * *}$ & $-0.248^{* * *}$ \\
\hline Children aged 8-12 years in household & 0.011 & 0.049 \\
\hline Children aged $13-18$ years in household & -0.046 & -0.029 \\
\hline Children older than 18 years in household & $-0.168^{* * *}$ & -0.074 \\
\hline Conventional or natural apples at home & -0.083 & 0.020 \\
\hline Conventional eggs at home & $0.226^{* * *}$ & 0.132 \\
\hline Conventional or natural broccoli at home & $0.317^{* * * *}$ & $0.304^{* * *}$ \\
\hline Looks at labels when buying new foods & $0.485^{* * *}$ & $0.490^{* * * *}$ \\
\hline Previously informed about organic foods & $-0.175^{*}$ & -0.097 \\
\hline Previously informed about natural foods & 0.073 & 0.029 \\
\hline Previously seen USDA organic seal & 0.053 & \\
\hline Previously seen natural claim & -0.069 & -0.060 \\
\hline Previously seen $70 \%$ organic claim & -0.184 & \\
\hline Previously seen "Made with Natural Ingredients" & -0.163 & -0.157 \\
\hline Broccoli & -0.050 & -0.050 \\
\hline Eggs & -0.045 & -0.045 \\
\hline Constant & -0.638 & $-0.322^{*}$ \\
\hline Observations & 273 & 273 \\
\hline$R^{2}$ & 0.220 & 0.184 \\
\hline$F$-statistic & $2.556^{* * * *}$ & $2.994^{* * * *}$ \\
\hline
\end{tabular}

Note: Significance is denoted as $*(\mathrm{p}<0.1), * *(\mathrm{p}<0.05), * * *(\mathrm{p}<0.01)$. Dependent variable in columns $(5)$ and $(6)$ is the WTP for conventional commodities subtracted from the WTP for natural commodities. The $F$-statistic for testing the null hypothesis that the coefficients on the regressors deleted in column (6) are jointly zero is 1.42 , with a p-value of 0.19 . 

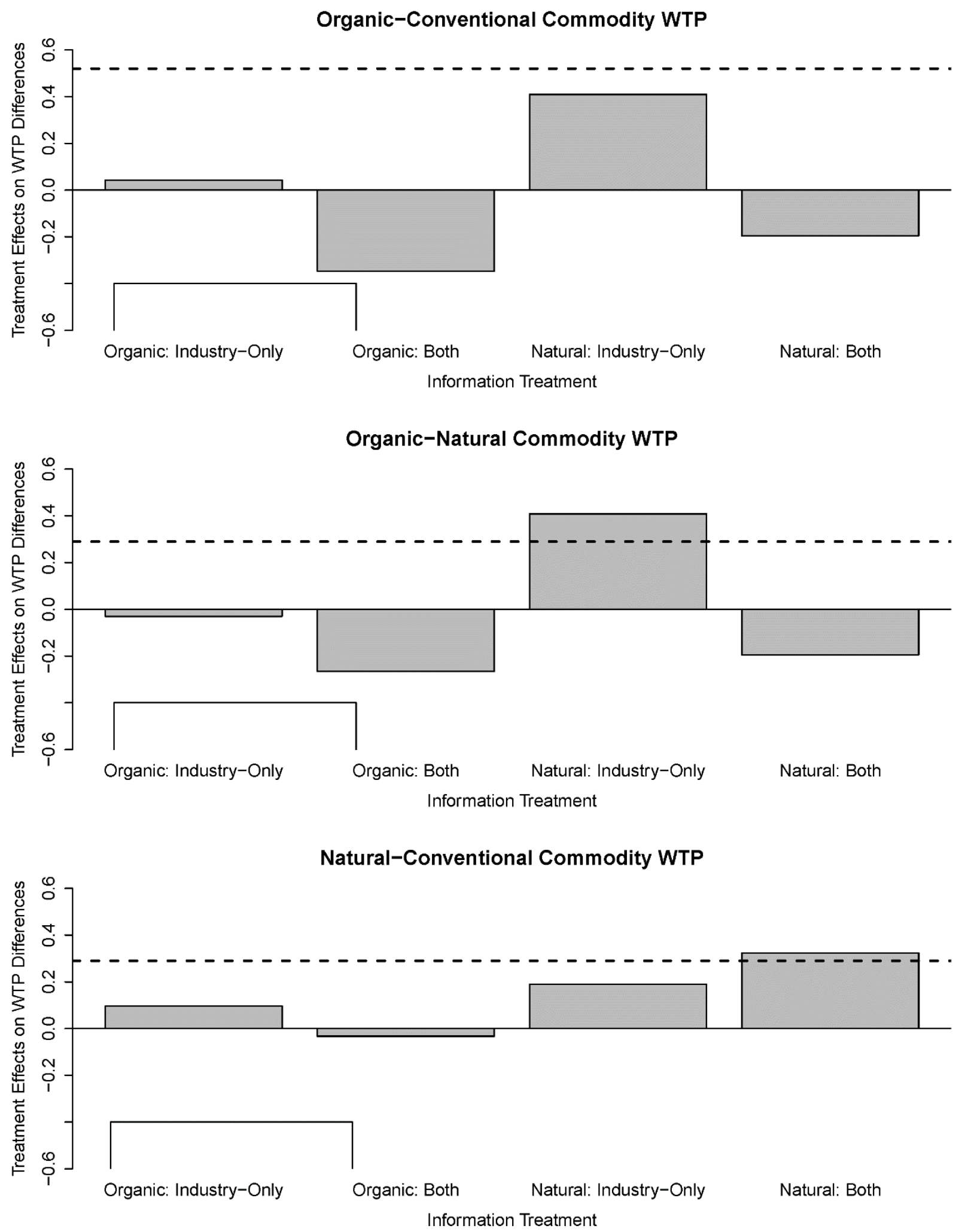

Fig. 3. Information treatment effects on WTP differences. 
Table 6. Expected value of third-party information

\begin{tabular}{lcc}
\hline & \multicolumn{2}{c}{ Switching: } \\
& Natural to Conventional & Organic to Conventional \\
\hline Apples (per 3 lbs.) & $\$ 2.90$ & $\$ 2.97$ \\
Eggs (per dz.) & $\$ 0.06$ & $\$ 0.00$ \\
Broccoli (per 1.25 lbs.) & $\$ 0.26$ & $\$ 0.10$ \\
\hline Note: Premium gains in the first column are calculated from sample sizes of 55, 36, and 50 subjects for apples, eggs, \\
and broccoli (respectively). Premium gains in the second column are calculated from sample sizes of 49, 36, and 50 \\
subjects for apples, eggs, and broccoli (respectively). The zero valuation of third-party information in switching \\
from organic to conventional eggs arises because the percentage switching is zero, i.e., the number of subjects \\
$\begin{array}{l}\text { buying conventional who received third-party organic information equals the number of subjects buying } \\
\text { conventional who received the organic industry information treatment. }\end{array}$
\end{tabular}




\section{Appendix}

Table A.1. Zero bids across commodities and types

\begin{tabular}{lccc} 
& Conventional & Natural & Organic \\
\hline Apples & $2(1.9 \%)$ & $3(2.9 \%)$ & $2(1.9 \%)$ \\
Eggs & $3(2.9 \%)$ & $4(3.9 \%)$ & $1(1.0 \%)$ \\
Broccoli & $1(1.0 \%)$ & $2(1.9 \%)$ & $0(0.0 \%)$ \\
\hline
\end{tabular}

Note: The first number in each entry is the count of zero bids. The second number in parentheses expresses each count as a fraction of the 102 bids per commodity and type. 
Fig. A.1. Organic food industry perspective on organic foods.

Please take a few minutes to read the following information.

\section{Organic Food Industry Perspective on Organic Foods}

The following is a statement on organic foods expressing the views of leaders in the organic food industry, including the Organic Trade Association, organic food cooperatives, and Whole Foods Market.

\section{General Statement:}

- In the United States, the sales of organic food have grown very rapidly. This growth in demand is driven by many consumers seeking out foods that are perceived to be more healthful, tastier and more environmentally friendly than conventional foods.

- The term "organic" refers to foods produced in compliance with a comprehensive list of regulations from the USDA.

- The production of organic fruits, vegetables, grains, legumes, and other agricultural commodities does not use synthetic fertilizers or pesticides, and animals that produce organic milk and eggs eat organic feed and do not receive growth hormones or antibiotics.

- Certain livestock have access to pasture or outdoor areas for specified periods of time. Organic farming procedures also recycle resources and promote biodiversity. In the US, foods that contain at least 95\% organic ingredients can be labeled as "organic" and carry the USDA organic seal

\section{USDA}

ORGAnIC

Many consumers feel a strong affinity toward organic, integrated farming systems relative to more specialized farming systems.

\section{Production Standards:}

- Organic production and processing methods do not use synthetic fertilizers and pesticides, antibiotics, growth hormones, genetically modified organisms, irradiation, or sewage sludge. Organic producers frequently advertise their products as being pesticide and GMO free and environmentally friendly. These producers frequently integrate crop and livestock operations.

- Livestock are especially valued on organic farms because their manure, along with legume hay and beans, are the main sources of fertilizer nutrients and organic matter needed for growing organic vegetables, grains and fruits. Organic farmers use crop rotation and intensive seedbed preparation to prepare fields for planting and to give organic plants a head start on weeds. Postemergent weed control is largely done by mechanical cultivation, mulching, and manually pulling weeds.

- Organic milk is produced from cows that are comfortably housed and obtain a significant amount of their feed from pasture grazing, with other feed coming from organic hay, grain and plant protein. Organic eggs are produced by hens that eat organic feed and are not kept in cages.

\section{Nutrition, Taste and Appearance:}

- The organic food industry sees organic foods as being more nutritious and tastier than conventional foods. In addition, The Organic Center has concluded that organic plant-based foods are on average nutritionally superior to conventional foods, especially when phytonutrients such as antioxidants are considered.

- Consumers purchase organic produce and eggs at local farmers markets because they believe that these foods are fresher, tastier and free of synthetic chemicals. For example, broccoli is considered to be one of the healthiest and most beneficial vegetables, containing vitamins and fiber, but organic broccoli is even better because of the rigorous production standards. One study found that organic apple puree contained more phenols, flavonoids and vitamin $\mathrm{C}$ than conventional apples. Apple puree is a popular food choice for babies, and if organic apples are used to make the puree, it is even better for children. 
Fig. A.2. Independent, third-party, verifiable perspective on organic foods.

Please take a few minutes to read the following information.

Independent, Third Party, Verifiable Perspective on Organic Foods

The following is a statement on organic foods by a third-party group consisting of individuals knowledgeable about organic production systems and foods, including scientists at several leading land-grant universities.

\section{General Statement:}

- In 2002, the Agricultural Marketing Service implemented national uniform standards for the US production and processing of organic foods. It includes a list of permitted (prohibited) methods and practices or substances that should (should not) be used in organic production, processing and handling by domestic or foreign producers. These standards are strictly process based and do not make any claims about the nutrient value or food safety of organic foods.

- A USDA-certified organic producer must prepare an organic production plan that follows the National Organic Program (NOP) and have it certified by a USDA accredited certifier, must maintain records of practices and material used, and have an annual inspection. The NOP prohibits the use of genetic modification, synthetic fertilizers, synthetic pesticides, sewage sludge, and irradiation in production or processing.

- Only farms and processors that are USDA-certified organic, where foods contain at least 95 percent

organic ingredients, can sell "organic" foods in the US and display the USDA's organic seal

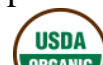
addition to natural foods grocery stores, organic foods are now available in almost all supermarkets and big box stores, such as Super Wal-Mart and Costco.

\section{Production Standards:}

- Producers and processors must follow production processes consistent with the NOP. Organic farmers must manage soil fertility and crop nutrients through tillage and cultivation practices, crop rotation, and cover crops, supplemented with animal and crop waste materials. This means that synthetic fertilizers, insecticides, herbicides and fungicides are "prohibited substances," but a few synthetic substances are permitted, such as vaccines to prevent livestock diseases, vitamins $\mathrm{B}_{1}, \mathrm{C}$, and $\mathrm{E}$ fortification of livestock feed, and the addition of selective soil micronutrients. Farmers can use organic pesticides or naturally occurring minerals but not synthetic pesticides.

- Organic producers must feed their livestock organic feeds, and livestock cannot be given growth hormones or antibiotics. Good management practices, including the use of vaccines, are to be used to reduce animal disease problems. All organically raised animals must be comfortably housed (no total and perpetual indoor confinement) and have access to the outdoors, including access to grazing pasture for ruminants and access to the outdoors for egg laying chickens. However, chickens are not required to be "free-range."

\section{Nutrition, Taste and Appearance:}

- A large amount of scientific evidence has concluded that organic foods are no more nutritious than conventional foods, but some antioxidants might be higher. However, pesticide levels on organic fruits and vegetables are lower than on conventional produce, both being below allowable Food and Drug Administration safety limits. In addition, organic chicken, pork and milk have reduced risk of antibiotics-resistant bacteria, but cage-free chickens have greater risk of exposure to bacteria in animal waste that they walk through, raising food safety risks for eggs from these birds.

- Organic foods do not necessarily taste better than conventional foods. Observed taste by a consumer is a result of personal preferences and degree of maturity of a product. Organic produce may have imperfect appearance — odd shapes, varying colors, smaller sizes, and blemishes because of the organic production process. In addition, organic produce may have a shorter shelf life or spoil faster because they are not treated with certain preservatives used on conventional produce. 
Fig. A.3. Natural food industry perspective on "natural" and "all-natural" foods.

Please take a few minutes to read the following information.

Natural Food Industry Perspective on "Natural and "All Natural" Foods

The following is a statement on Natural or All Natural foods expressing the views of leaders in the natural foods industry, including Trader Joe's brands, Kashi and Wildtree.

\section{General Statement:}

- Natural food websites describe all natural or natural foods as being fresher, better tasting, and containing fewer processed ingredients than conventional foods. In particular, a number of websites tote the health benefits of eating whole grains, fresh fruits and vegetables, grass fed beef and lamb, and free-range pigs and chickens, including the chicken's eggs.

- This emphasis on minimal processing of grains, fruits and vegetables and a natural environment for farm livestock and poultry is represented as a source of especially healthful food and a pleasant environment for farm animals. All natural fruits and vegetables are fresher, tastier and nutritious, and they have fewer food safety concerns than more processed foods. Consequently, many health benefits arise for those consuming natural or all natural food products.

\section{Production Standards:}

- To preserve the natural integrity of farm produced food, the only processes that should take place are physical processes that do not fundamentally alter a raw product or that only separate a whole intact food into component parts, i.e., smoking, roasting, freezing, drying, and fermenting.

- All natural free-range eggs are produced by hens that are allowed to roam freely within a farmyard, a shed or chicken coop, which permits large amounts of exercise, rather than being confined to cages. In addition, this free-ranging also allows the hens to consume a more varied diet and to experience natural sunlight, which make eggs taste better.

\section{Nutrition, Taste and Appearance:}

- While taste is subjective, many consumers believe that all natural and natural foods taste better than conventional foods. The potential health benefits from consuming an all natural and natural food diet include reduced consumption of potentially harmful substances such as hormones, pesticides, fertilizers and artificial ingredients.

- Consumers may be sensitive to some of these substances such as MSG, a common flavorenhancer, and dyes used for food coloring. For some consumers, elimination of these sources of sensitivity may improve how they feel.

- In addition, minimally processed all natural or natural foods are more likely to contain whole food sources of beneficial nourishment, including fiber, complex carbohydrates, vitamins, and minerals. To the extent that a consumer's current diet is deficient in fiber, complex carbohydrates or vitamins, incorporating large amounts of all-natural foods can be expected to improve his or her health. 
Fig. A.4. Independent, third-party, verifiable perspective on natural foods

Please take a few minutes to read the following information. Independent, Third-Party Verifiable Perspective on Natural Foods

The following is a statement on "Natural" or "All Natural" foods by a third-party group consisting of individuals knowledgeable about natural foods, including scientists at several leading land-grant universities.

\section{General Statement:}

- In the United States, neither the Food and Drug Administration (FDA) nor the United States Department of Agriculture (USDA) has a formal definition of the term "natural" or "all natural." From a food science perspective, it is difficult to define a food product to be "natural" or "all natural" since food is often processed and no longer a product of the earth.

- Although the Food and Drug Administration (FDA) does not formally define the term "natural" or "all natural" for the food industry, it also does not object to the use of the term for food products that are free of synthetic or artificial ingredients and are minimally processed and without preservatives, artificial additives, growth hormones, antibiotics, hydrogenated oils, stabilizers and emulsifiers. Despite these terms being applied to many foods, the "natural" and "all natural" concept remains ambiguous, and the FDA discourages the food industry from using these terms on food labels in a manner that the agency views as misleading or deceptive.

\section{Production Standards:}

- Currently, only very weak production requirements exist for food products labeled as "natural" or "all natural" in the United States. The USDA's Food Safety and Inspection Service (FSIS) suggests the term "natural" or "all natural" for products containing no artificial ingredients or chemical preservatives and with minimal processing, such as traditional processes used to make food edible, safe for human consumption or for preservation, i.e. smoking, roasting, freezing, drying, and fermenting. More severe processing such as acid hydrolysis and chemical bleaching is considered more than minimally processed.

- "Natural" and "all natural" food products do not follow the production protocols of organic food production; rather, they aim to preserve the natural integrity of the food products as they come from the fields and farms. However, several lawsuits have been filed against major national brands that may have used the "natural" or "all natural" label deceptively. These brands include Tostitos, Sun Chips, Kashi, Snapple, Tropicana, Naked Juice, Jamba Juice, Ben and Jerry's, and Campbell Soup. Many of these suits are currently ongoing, although some have been dismissed or partially dismissed by federal judges.

\section{Nutrition, Taste and Appearance:}

- While consumers may think the terms "natural" and "all natural" imply "healthy," these food products may be less safe than similar conventional items. In 2002, records from the FDA and Health Canada revealed that some organic and "all natural" products were eight times more likely to be recalled for food safety problems, including bacterial contamination and mislabeling, than conventional foods.

- Furthermore, a large amount of scientific research does not conclude that "natural" or "all natural" foods are more nutritious than conventional foods. However, evidence from the United States FDA found that 6 out of 10 United States shoppers believe that "natural" and "all natural" foods are healthier than conventional foods. . 